\title{
Toward mapping crop progress at field scales through fusion of Landsat and MODIS imagery
}

\author{
Feng Gao ${ }^{\mathrm{a},}$, , Martha C. Anderson ${ }^{\mathrm{a}}$, Xiaoyang Zhang ${ }^{\mathrm{b}}$, Zhengwei Yang ${ }^{\mathrm{c}}$, Joseph G. Alfieri ${ }^{\mathrm{a}}$, William \\ P.Kustas ${ }^{\mathrm{a}}$, Rick Mueller ${ }^{\mathrm{c}}$, David M. Johnson ${ }^{\mathrm{c}}$, John H.Prueger ${ }^{\mathrm{d}}$ \\ ${ }^{a}$ USDA, Agricultural Research Service, Hydrology and Remote Sensing Laboratory, 10300 \\ Baltimore Avenue, Beltsville, MD 20705, USA \\ ${ }^{\mathrm{b}}$ Geospatial Sciences Center of Excellence and Department of Geography, South Dakota State \\ University, Brookings, SD 57007, USA \\ ${ }^{\text {c } U S D A, ~ N a t i o n a l ~ A g r i c u l t u r a l ~ S t a t i s t i c s ~ S e r v i c e, ~} 3251$ Old Lee Highway, Fairfax, VA 22030, USA \\ ${ }^{\mathrm{d}}$ USDA, Agricultural Research Service, National Laboratory for Agriculture and the Environment, \\ Ames, IA 50011, USA
}

\begin{abstract}
The ability to regionally monitor crop progress and condition through the growing season benefits both crop management and yield estimation. In the United States, these metrics are reported weekly at state or district (multiple counties) levels by the U.S. Department of Agriculture (USDA) National Agricultural Statistics Service (NASS) using field observations provided by trained local reporters. However, the ground data collection process supporting this effort is time consuming and subjective. Furthermore, operational crop management and yield estimation efforts require information with more granularity than at the state or district level. This paper evaluates remote sensing approaches for mapping crop phenology using vegetation index time-series generated by fusing Landsat and MODIS (Moderate Resolution Imaging Spectroradiometer) surface reflectance imagery to improve temporal sampling over that provided by Landsat alone. The case study focuses on an agricultural region in central Iowa from 2001 to 2014. Our objectives are 1) to assess Landsat-MODIS data fusion results over cropland; 2) to map crop phenology at 30m resolution using fused surface reflectance data; and 3) to identify the relationships between remotely sensed crop phenology metrics and the crop progress stages reported by NASS. The results show that detailed spatial and
\end{abstract}


temporal variability in vegetation development across this landscape can be identified using the

30 fused Landsat-MODIS data. The mean difference (bias) in Normalized Difference Vegetation Index 31 (NDVI) between actual Landsat observations and the fused Landsat-MODIS data, generated for 32 Landsat overpass dates, is in the range of -0.011 to 0.028 for every year. The derived phenological 33 metrics show distinct features for different crops and natural vegetation at field scales. Strong correlations are observed between remotely sensed phenological stages, based on NDVI curve inflection points, and the observed crop physiological growth stages from the NASS Crop Progress (CP) reports. The green-up dates detected from remote sensing data typically occurred during crop vegetative stages when 2-4 leaves were developed for both corn and soybeans, or about 1-3 weeks after the reported emergence dates when the plant were first visible to ground-based observers. Despite being a lagging indicator, remotely sensed green-up can be used effectively to backcast emergence, e.g. as input to spatially distributed crop models. The differences in green-up date between corn and soybean were 8-10 days, consistent with the offset in emergence dates reported by NASS at district level. The reported harvest dates were typically about 2-3 weeks after the dormancy stage was detected via remote sensing for corn and about 1-2 weeks for soybeans. This suggests that probable harvest times for individual fields may be predicted 1-3 weeks ahead using remote sensing data. The results suggest that crop phenology and certain growth stages at field scales (30m spatial resolution) can be linked and mapped by integrating imagery from multiple remote sensing platforms.

Keywords: crop growth stages, phenology, crop conditions, crop progress, crop yield, data fusion, time-series analysis

\section{INTRODUCTION}

Accurate spatiotemporal information about crop progress and condition during the growing season is critical for crop management and yield estimation (Walthall et al., 2012; Sakamoto et al., 2013). The amount of yield loss realized during a drought year is dependent on the crop growth stage when water stress occurs. For this reason, irrigation applications may be modulated depending on crop growth stage. Crop progress provides information necessary for efficient irrigation and drainage management. For example, the most beneficial timing for irrigation is during the latter part 
addition, crop progress information is critical for scheduling fertilization, pest management and harvesting operations at optimal times for achieving higher yields. For food security and commodity trading, it is vital to estimate crop yield before harvest. Crop progress and growth condition data sets provide information that is needed for yield estimation.

Crop progress varies by year and location and is affected by climate variation, local weather, soil properties, environmental changes and anthropogenic activities. Over the past three decades, both corn and soybean in the U.S. have been planted increasingly earlier in the spring. Corn planting dates have advanced by 10 days and soybean by 12 days from 1981 to 2005 (Kucharik, 2006; Walthall et al., 2012). This earlier planting has been accompanied by a longer growing season, both of which contribute to yield increases. These trends can also be observed from U.S. Department of Agriculture (USDA) National Agricultural Statistics Service (NASS) publications on the planting and harvesting dates for field crops (NASS Field Crops, 1997, 2010). In addition to climate and local weather variation, crop phenology trends also reflect changing farm management strategies and development of new cold-hardy genotypes (Kucharik, 2006). High spatial resolution information about relative changes in characteristic phenology due to varying climate and anthropogenic activities are important for understanding vegetation responses to climate variation, and for facilitating better decision making to mitigate drought impacts and to support adaptation strategies.

In the United States, crop progress and condition are estimated by USDA NASS using ground survey data supplied by $\sim 4000$ reporters. These reporters provide visual observations and subjective estimates of crop progress based on NASS standard definitions. Crop growth stages, crop conditions and farmers' activities are reported each week. The NASS Crop Progress (CP) reports are summarized and released weekly during the growing season from early April to late November (NASS CPR, 2015). Weekly CP reports are among the most requested publications released by NASS and have substantial impacts for future crop market prices (Lehecka, 2014). Even though the weekly reports have been carefully checked for data consistency, the ground data collection is time consuming and subjective. The quality of crop progress and condition assessments depends on the individual reporter's experience and subjective judgment. The report provides the public with summaries at the agricultural statistic district (multiple counties) and state level. These reports do not discuss spatial variability within the agricultural statistical unit. For many applications such as 
Remote sensing data can be an effective supplement to ground-based observation, providing spatial and temporal information for vegetation monitoring over large areas. In recent years, timeseries of coarse resolution data, such as from the Advanced Very High Resolution Radiometer (AVHRR) and the Moderate-resolution Imaging Spectroradiometer (MODIS), have been used to extract vegetation phenology (Reed et al., 1994; Zhang et al., 2003; Jonsson and Eklundh, 2004; Zhao et al., 2009, 2012). These approaches use mathematical functions to fit time-series of vegetation indices (VIs). Vegetation phenology or phenological parameters are extracted based on either a predefined VI threshold (Reed et al. 1994; Jonsson \& Eklundh, 2004) or the inflection points of the fitting function (Zhang et al., 2003). Using 4 years of time-series AVHRR NDVI data, Reed et al. (1994) generated 12 phenological metrics including the onset of greenness, time of peak NDVI, maximum NDVI, rate of green-up, rate of senescence, and integrated area under the curve. Jonsson and Eklundh (2004) developed a software tool (TIMESAT) to analyze time-series VI data based on three fitting approaches (asymmetric Gaussians, double logistic function, and Savitzky-Golay filter). Eleven phenological parameters are extracted based on the fitting functions and the pre-defined threshold. Zhang et al. (2003; 2015) developed a phenology program using a hybrid piecewise logistic function and the approach has been used to produce the MODIS phenology data product since 2001. All these approaches extract vegetation phenology using particular features in timeseries VI data, which can be interpreted as remote sensing phenology. In order to relate phenology detected from remote sensing signals to the field observed crop progress (or physiological stages), Sakamoto et al., (2010, 2011) developed a two-step filtering approach to detect maize and soybean phenology using MODIS data. In their approach, a shape-model of Wide Dynamic Range Vegetation Index (WDRVI) was defined for each crop. The shape-model serves as a priori information to fit observed MODIS WDRVI data. The phenological stages were computed (or modified from a priori) based on the fitting parameters. The approach was applied to map crop

112 progress in the U.S. Corn Belt using MODIS data (Sakamoto et al., 2011) and to estimate corn grain 113 yield at the state level (Sakamoto et al., 2013). Zhao et al., (2012) assessed the impact of the 114 temporal resolution of the input image timeseries on the accuracy of the remote sensing based 115 phenology estimation. These studies reveal that dense time-series remote sensing data provide better 116 temporal information for mapping vegetation phenology at coarse spatial resolution. 
117 Global land cover and land surface phenology products are available at 500m MODIS spatial 118 resolution (Friedl et al., 2002; Zhang et al., 2003). However, the 500m spatial resolution is still too 119 coarse for many crop fields. It often represents mixtures of vegetation or crop types which may have 120 very different phenological growth cycles. Crop phenology is most appropriately investigated at 121 field scales, well-supported in the United States by the Landsat spatial resolution in the reflectance bands $(30 \mathrm{~m})$. Spatial details at this resolution can be well captured in land cover and land use 123 classification (Loveland \& Dwyer, 2012; Roy et al., 2014). The USDA NASS produces the 124 Cropland Data Layer (CDL) in the United States annually at 30-m resolution (Boryan et al., 2011) using a combination of Landsat, Disaster Monitoring Constellation UK-2 and Deimos-1 imagery 126 (NASS CDL, 2015). It would be ideal to have crop progress information at the same spatial resolution for crop management and yield estimation. However, Landsat and medium-resolution satellite imagery are normally acquired over a narrow swath and thus the revisiting cycles are relatively long (from a few days to over 20 days). The lack of frequent medium-resolution data is a major barrier to mapping crop phenology and progress at field scales.

Landsat data have been freely available since 2008 (Woodcock et al., 2008). Landsat 5 was

132 launched on March 1, 1984. The Thematic Mapper (TM) instrument aboard Landsat 5 provided 30133 m resolution data for over 28 years until 2012. Landsat 7 was launched on April 15, 1999, carrying 134 the Enhanced Thematic Mapper (ETM+). Despite the failure of the scan-line-corrector (SLC) which 135 causes data gaps in the ETM+ imagery, Landsat 7 is still providing useful information over about $13680 \%$ of a given Landsat scene. Landsat 8 was launched on February 11, 2013. The Operational Land 137 Imager (OLI) instrument aboard Landsat 8 provides high quality 30-m resolution shortwave data on 138 a 16 day repeat cycle. The Landsat TM, ETM+ and OLI data have been processed to surface 139 reflectance using a MODIS-like atmospheric correction approach (Vermote et al. 2002; Masek et al., 140 2006) and can be downloaded from the US Geological Survey (USGS) Earth Resources Observation 141 Systems (EROS) data center. The recently launched Multispectral Imager on Sentinel-2A mission by 142 European Space Agency has a global acquisition plan and the data products will be freely available.

143 The effective revisit cycle could be shortened to a few days if Landsat and Sentinel-2 data sets are 144 combined.

145 Until more frequent Landsat-resolution imagery becomes available, data fusion techniques 146 provide a solution for bridging between Landsat observations using high temporal resolution 
147 MODIS data collected at somewhat coarser spatial scales. This data fusion approach (Gao et al., 148 2006; Hilker et al., 2009; Zhu et al., 2010) combines the spatial resolution of Landsat with the 149 temporal frequency of MODIS and thus provides a feasible and economic solution for integrating 150 remote sensing data from different satellite sources. The Spatial and Temporal Adaptive Reflectance 151 Fusion Model (STARFM) uses comparisons of one or more pairs of observed Landsat/MODIS 152 maps, collected on the same day, to predict maps at Landsat-scale on other MODIS observation 153 dates (Gao et al., 2006; 2015). STARFM was subsequently modified and extended for different 154 applications to form the Spatial Temporal Adaptive Algorithm for mapping Reflectance Change 155 (STAARCH) for detecting reflectance changes associated with land cover change and disturbance 156 (Hilker et al., 2009), and an enhanced STARFM (ESTARFM) approach developed to handle more 157 heterogeneous scenes, where "pure" pixels are lacking (Zhu et al., 2010). Walker et al (2012) used 158 the STARFM data fusion approach to generate synthetic imagery for tracking phenological changes 159 over a dryland vegetation site in Arizona. Liang et al. (2014) compared the land surface phenology 160 derived from MODIS and the fused Landsat-MODIS data to ground measurements and found that 161 the fused Landsat-MODIS data can better capture land surface phenology at the community level 162 (0.1-20ha) in a northern U.S. mixed forest than using MODIS alone.

163 Here we extend the application of data fusion down to sub-field scales for phenology mapping 164 over agricultural landscapes. The main objective of this paper is to test the ability of this Landsat165 MODIS data fusion methodology to map crop phenology at 30-m resolution, where crop growth 166 stages for different crops can be distinguished. Specifically this paper aims: 1) to generate and 167 evaluate the fused Landsat-MODIS daily surface reflectance and the derived NDVI at 30-m 168 resolution over an intensively cropped area; 2) to map crop phenology at 30m resolution (sub-field 169 scale) using the fused Landsat-MODIS data; and 3) to identify the relationships between crop 170 phenology detected from remote sensing data and the crop progress stages reported by NASS. Our 171 study focuses on an agricultural area in central Iowa, USA from 2001 to 2014. 
2.1 Study Area

175

Fig. 1 shows the study area in central Iowa overlaid with the Landsat scene (path 26 and row 31).

176 This is a rain-fed agricultural area in the U.S. Corn Belt region. Corn and soybean are the major

177 cover types, and these crops are typically rotated in consecutive years. Major natural vegetation

178 types include deciduous forest and grasslands. There are also small portions of developed surfaces

179 (roads and buildings) in the area. The Landsat scene covers the South Fork watershed (subset

180 window), and includes a USDA Agricultural Research Service (ARS) Long Term Agricultural

181 Research (LTAR) site instrumented with micrometeorological flux towers. This study site is located 182 in the middle of the U.S. Corn Belt and rain-fed Corn Belt area.

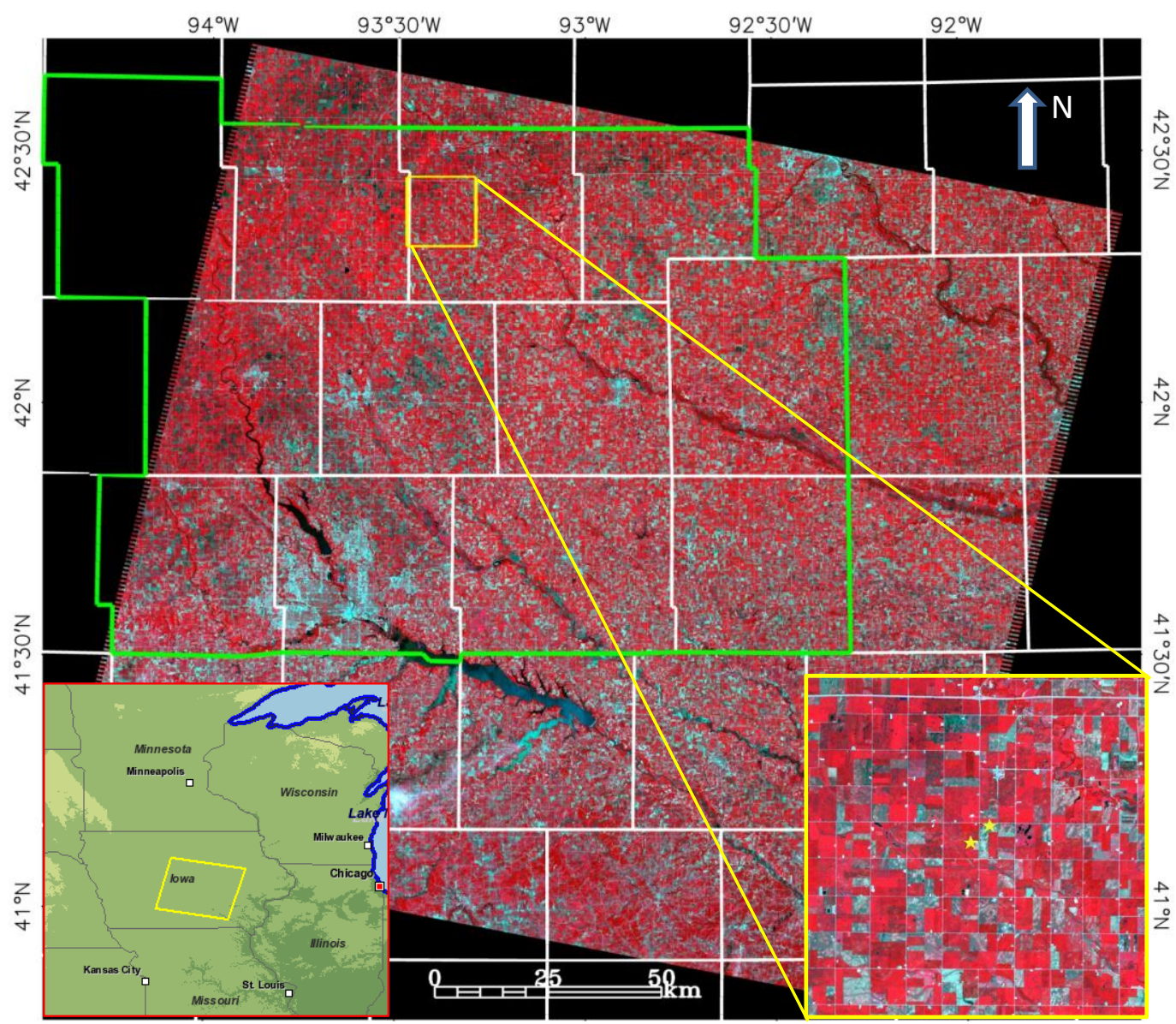

Fig. 1. Landsat scene (path 26 and row 31) containing the research area (central Iowa, yellow polygon in lower left map) overlaid with county boundaries (white lines), agricultural district 
187 boundaries (central Iowa, green polygon), and two flux tower sites (yellow stars in lower right

188 image). The subset area in the lower right was chosen to demonstrate results for better visualization.

\subsection{Crop Progress Reports}

191 USDA NASS publishes weekly Crop Progress (CP) reports quantifying the cumulative progress for major crops at the key growth stages in terms of percentages. The key physiological growth stages are defined by NASS as shown in Table 1 (extracted from the NASS Terms, 2015)

Table 1. Key growing stages and descriptions for corn and soybeans from NASS

\begin{tabular}{|l|l|l|l|l|}
\hline Corn & Definition & Soybeans & Definition & $\begin{array}{l}\text { Phenology from } \\
\text { Remote Sensing }\end{array}$ \\
\hline Emerged & $\begin{array}{l}\text { As soon as the plants are } \\
\text { visible }\end{array}$ & Emerged & $\begin{array}{l}\text { As soon as the plants are } \\
\text { visible }\end{array}$ & Green-up \\
\hline Silking & $\begin{array}{l}\text { The emergence of silk-like } \\
\text { strands from the end of ears }\end{array}$ & Blooming & $\begin{array}{l}\text { A plant should be considered } \\
\text { as blooming as soon as one } \\
\text { bloom appears. }\end{array}$ & Mid-season \\
\hline Dough & $\begin{array}{l}\text { Normally half of the kernels } \\
\text { are showing dent with some } \\
\text { thick or dough-like substance } \\
\text { in all kernels }\end{array}$ & $\begin{array}{l}\text { Setting } \\
\text { Pods } \\
\text { fully dented and the ear is firm } \\
\text { and solid }\end{array}$ & $\begin{array}{l}\text { Pods are developing on the } \\
\text { lower nodes with some } \\
\text { blooming still occurring on } \\
\text { the upper nodes }\end{array}$ & Mid-season \\
\hline Dent & $\begin{array}{l}\text { Plant is considered safe from } \\
\text { frost. Corn is about ready to } \\
\text { harvest with shucks opening } \\
\text { and there is no green foliage } \\
\text { present }\end{array}$ & $\begin{array}{l}\text { Leaves } \\
\text { Mature }\end{array}$ & $\begin{array}{l}\text { Leaves near the bottom of the } \\
\text { plant are yellow and } \\
\text { dropping, while leaves at the } \\
\text { very top may still be green. } \\
\text { Leaves are 30-50 percent } \\
\text { yellow }\end{array}$ & Dormancy \\
\hline Harvest & \begin{tabular}{l} 
Mid-season \\
\hline
\end{tabular} & Harvest & Dormancy \\
\hline
\end{tabular}

196 District-level crop progress reports from 2010 to 2014 were obtained from the NASS public website (NASS CPR, 2015). Data for the "central Iowa" district (green polygon in Fig. 1) were extracted, mainly coinciding with the processed Landsat scene (p26r31). In addition, county-level crop progress data for 2010 and 2011 for 17 counties completely covered by the Landsat scene were obtained directly from NASS under a signed confidentiality agreement, and were quality controlled

201 for obvious data entry errors. These data are proprietary; therefore, to maintain the confidentiality of 202 the raw data and the observation locations, the associated county name and actual ID Numbers are 
not revealed in this study. For these reasons, the analyses in this paper mainly rely on the published 204 district level data.

\subsection{Landsat and MODIS data}

Nine years of Landsat and MODIS data from 2001 to 2014 were chosen to generate the fused Landsat-MODIS reflectance time-series for crop phenology mapping. Fig. 2 shows Landsat dates for the selected years that were used in the study, including all clear and partially clear Landsat 5,7 , and 8 images. All Landsat images were evaluated visually, and the cloud mask distributed with the Landsat surface reflectance data products (Zhu \& Woodcock, 2012; 2015) was consulted to eliminate use of cloudy pixels/scenes in the data fusion and phenology processes. Only mostly clear Landsat scenes (dots in time axis for each year) were used as fine resolution images to pair with MODIS data as input to STARFM. Partially clear Landsat images (dots below the time axis for each year) were not used in the data fusion process. Landsat 7 images (yellow dots) that suffer SLC failure after May 2003 were not used as input pair images since SLC-off gaps will remain in the fused images and affect the subsequent phenology mapping. However, all valid and clear pixels (as identified in the cloud mask) from all available Landsat images, including partially clear and Landsat 7 SLC-off images, were used in the phenology mapping itself. From 2001 to 2011, Landsat 5 TM (red dots) and Landsat 7 ETM+ data were used. For 2013 and 2014, Landsat 7 ETM+ and Landsat 8 OLI (green dots) data were used. The vertical lines bracket prediction periods where a given Landsat-MODIS image pair was used as input to the data fusion process. The period for data fusion using that pair was determined using the maximum correlation criteria as described later in section 3.1 .

The required MODIS data products for the selected years from 2001 to 2014 were ordered and processed. These include the daily surface reflectance at both 250m (MOD09GQ) and 500m (MOD09GA) resolution (Vermote et al., 2002), the MODIS Bidirectional Reflectance Distribution Function (BRDF) parameters at 500m resolution (MCD43A1; Schaaf et al., 2002), and the MODIS land cover types at 500m resolution (MCD12Q1; Friedl et al., 2002). In order to cover the entire Landsat scene (path 26 and row 31), two MODIS tiles (h10v04 and h11v04) were ordered and mosaicked. MODIS Collection 5 data products were used in this study. 
232 Selection of years used in the analyses (Fig. 2) was governed by data availability. For 2010233 2014, when NASS CP reports for central Iowa (district level) were available for assessment, all 234 years were processed except 2012. In 2012, Landsat 5 TM reached the end of its serviceable life and 235 only MSS data were collected in the study area, while Landsat 7 ETM+ images suffer SLC-off gaps. 236 The only available Landsat images for 2012 are the Landsat 7 SLC-off ETM+ images. For this 237 reason, 2012 was not processed and analyzed. Prior to 2010, every 1-3 years were sampled for 238 analysis of inter-annual variations. In these earlier years, NASS CP reports are only available at the 239 state level, and ground observations and flux tower measurements were not available. Still, these 240 earlier years allow us to investigate the inter-annual variation of crop phenology over a wider time 241 range.

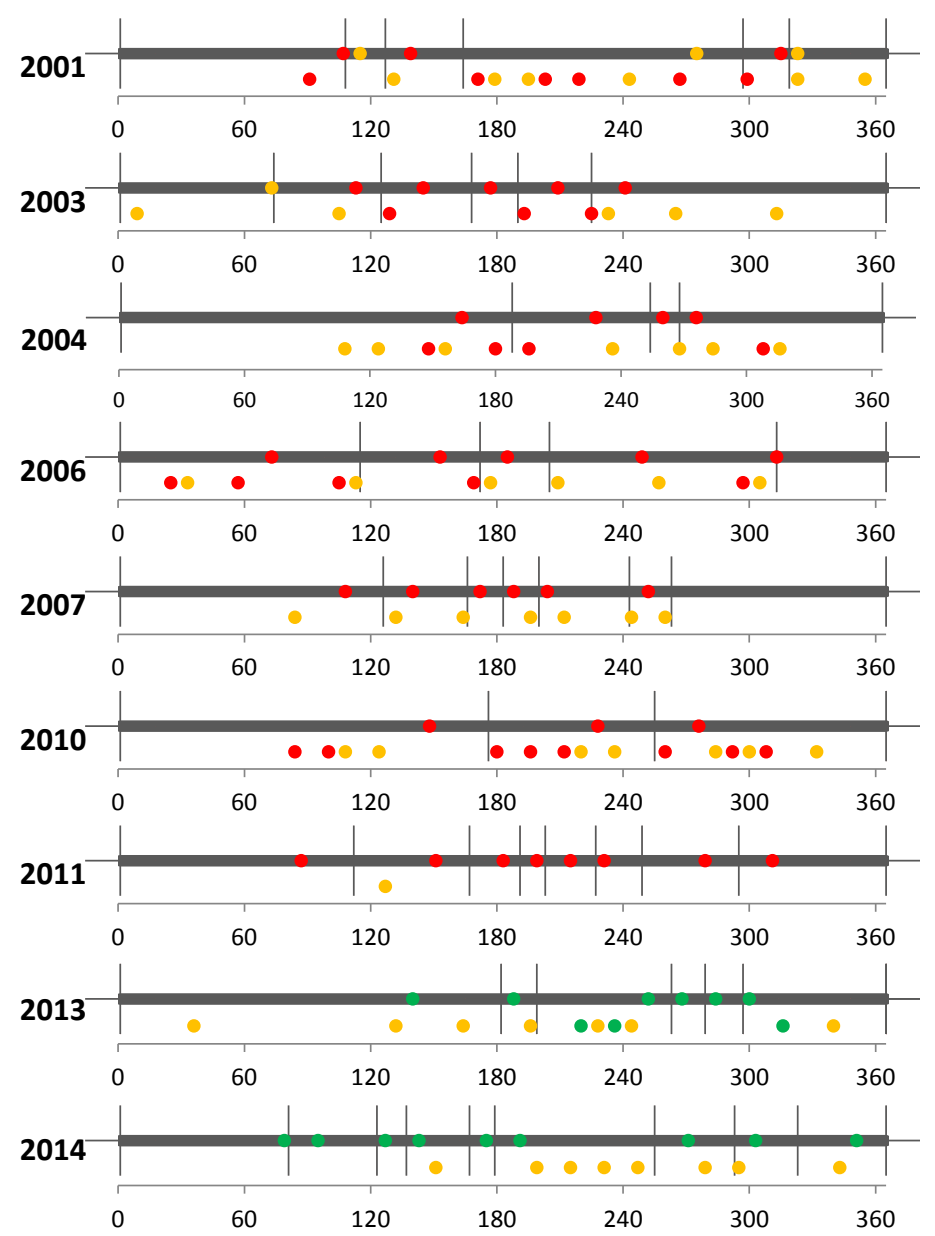

243 Fig. 2. Landsat images from 2001-2014 that were used in data fusion and crop phenology mapping.

244 Each dot represents a Landsat acquisition, while the vertical lines bracket prediction periods where a 
245 given Landsat-MODIS image pair was used as input to the data fusion process. Dots within the time 246 (x) axis indicate Landsat images that were used as pair images in the data fusion process; dots below 247 the time axis represent Landsat images that were not used in data fusion but used in phenology 248 mapping. Red, yellow, and green dots represent Landsat 5 TM (2001-2011), Landsat 7 ETM+ and 249 Landsat 8 OLI respectively.

250

251

$252 \quad 2.4$ Cropland Data Layer (CDL)

253 The Cropland Data Layer provides crop type information at field scales (Boryan et al., 2011). 254 NASS CDL 30-m resolution data from 2001 to 2014 were downloaded and used to analyze the crop 255 phenology patterns for major crop types over the study area. CDL products prior to 2006 were 256 generated based on Landsat 5/7 imagery. From 2006 to 2008, imagery from other satellites/sensors 257 including the Advanced Wide Field Sensor (AWiFS) on IRS-P6 and MODIS NDVI on Terra were 258 used in the CDL production. The CDL products were derived using Landsat imagery from 2008 and 259 2009. The CDL program used the Disaster Monitoring Constellation (DMC) satellites (i.e., Deimos2601 and UK-2) and Landsat 5/7 imagery since 2011 and Landsat 8 OLI imagery since 2013. In Iowa 261 from 2001 to 2014, the overall classification accuracies for major crops (soybeans and corn) are 262 generally above 96\%, except for 2001 (92-95\%). Soybean and corn crops were normally rotated in 263 two consecutive years although there are some variations due to the implementation of new 264 bioenergy policies (Ren et al., 2014). All CDL data were reprojected and resampled to match the 265 Landsat scene (path 26 and row 31).

\section{5 Flux Tower Data}

268 In-situ meteorological and surface flux measurements were collected over a pair of adjacent 269 agricultural fields north of Ames (near Buckeye), IA in Hardin County. The fields are nominally 800 $270 \mathrm{~m}$ by $800 \mathrm{~m}$ in size and characterized by flat terrain and clay loam soils. They are managed 271 following a maize/soybean rotation strategy, with the crop type alternating between the two fields on 272 an annual basis. 
The micrometeorological system deployed in each field was equipped with a sonic anemometer (CSAT3, Campbell Scientific Inc., Logan, Utah ${ }^{1}$ ) to measure the orthogonal wind velocity components and an open-path infrared gas analyzer (LI-7500, Li-COR Biosciences, Lincoln, Nebraska) to measure both water vapor and carbon dioxide concentration. The flux data were postprocessed using the full complement of standard corrections and adjustments. Nonphysical values and outliers were removed without replacement from the high -frequency $(20 \mathrm{~Hz}) \mathrm{data}$ using a moving window algorithm based on the method outlined by Goring and Nikora (2002). The halfhourly corrected fluxes were used to generate the daily mean data used in this analysis. The gross primary production (GPP) for the corn and soybean sites was derived from the measured daytime net ecosystem exchange (NEE) and the daytime ecosystem respiration (RE) estimated using regression equations between nighttime NEE and soil temperature (Xiao et al., 2004). We chose a simple empirical approach to estimate GPP since our objective is to examine the temporal trends of NEE/GPP in comparison to time-series NDVI during different crop growth stages. More accurate partitioning approaches need to include additional meteorological forcing variables and may consider ecosystem model inversion techniques.

\subsection{Field Biophysical Data}

Field observations of crop progress were conducted during growing seasons from 2010 to 2013, sampling two observation sites in Dallas County, Iowa located within the study area. The observation sites were at least 300 yards $(274 \mathrm{~m})$ away from other crop fields, major roads, buildings, and rivers etc. The observation fields selected were at least 50 acres $\left(0.202 \mathrm{~km}^{2}\right)$ in size with a regular shape (not elongated or concave) so that the fields cover sufficient pure image pixels. Each site was located inside a single homogenous crop field (either corn or soybean) representing field conditions and farm practices typical for the region. Fifteen plants each for corn and soybeans were systematically selected at geolocated sites within the fields following specific documented procedures. The vegetative crop growth progress stages of every selected corn and soybeans plants were observed and recorded weekly at fields by enumerators after planting. The height of each plant was measured and recorded every week. The overall crop growth stage for each crop was

\footnotetext{
${ }^{1}$ Mention of trade names or commercial products in this article is solely for the purpose of providing specific information and does not imply recommendation or endorsement by the U.S. Department of Agriculture.
} 
301 determined by the majority growing stage observed. Photographs of every sampled plant were 302 acquired with a GPS enabled digital camera for quality control and validation. Observations from 303 these two sites were compared to phenological metrics retrieved in the associated Landsat pixels.

\section{METHODS}

306 The analyses conducted in this study include two core components: data fusion and phenology 307 extraction. The entire processing flow chart is shown in Fig. 3, and briefly summarized here. In the 308 data fusion process, MODIS daily directional surface reflectance products are corrected to daily 309 nadir BRDF-adjusted reflectance (NBAR). In this study, the Landsat Digital Numbers (DN) were

310 calibrated and atmospherically corrected using the Landsat Ecosystem Disturbance Adaptive 311 Processing System (LEDAPS) (Masek et al., 2006). The Landsat surface reflectance can also be 312 directly ordered and downloaded from the USGS EROS data center. Landsat and MODIS 313 reflectances in the red and near infrared bands are then fused using the STARFM approach (Gao et 314 al., 2006). The phenology extraction process was applied to NDVI timeseries generated using both 315 the fused Landsat-MODIS surface reflectances and the observed reflectances acquired directly on 316 Landsat days. Crop phenological dates and metrics extracted from remote sensing data were 317 assessed in comparison with carbon flux measurements, field observations, and crop progress 318 statistics obtained from NASS CP reports at both the county level (under a signed confidentiality 319 agreement) and the district level (from the public web site). Key techniques and methods are 320 described below. 


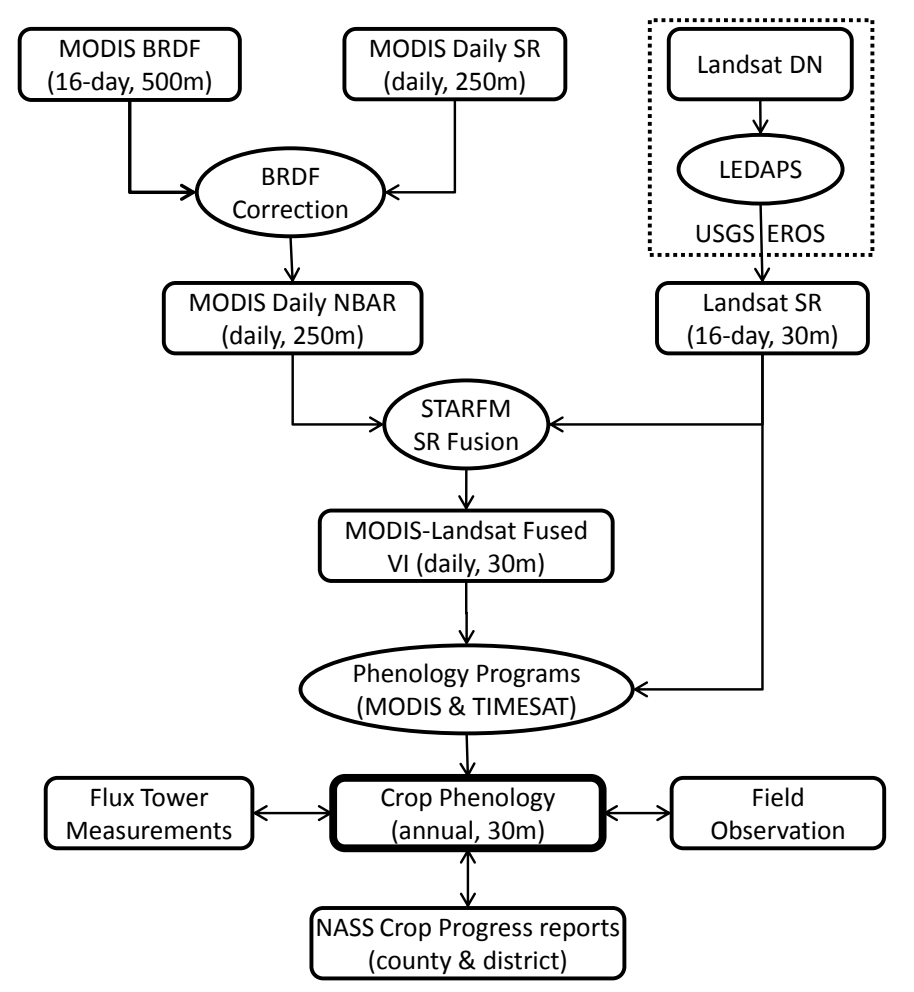

Fig. 3. Crop phenology data processing and analysis flow chart (rectangles indicate data

323 products and ellipses represent processing steps/modules).

\subsection{Landsat-MODIS Data Fusion}

The STARFM data fusion approach has been described in detail in Gao et al. (2006). An operational data fusion system has been developed to process MODIS and Landsat surface

328 reflectance data semi-automatically (Wang et al., 2014). This system implemented several 329 procedures to improve computational efficiency (Gao et al., 2015), consistency between Landsat and 330 MODIS inputs, and to automate selection of an optimal Landsat-MODIS input pair for each 331 prediction date. Some issues of relevance to routine phenology mapping are discussed in further 332 detail in this section.

\section{3.1.1 Data Consistency between Landsat and MODIS}

334 The data fusion algorithm requires that input data from the sensors to be fused are reasonably 335 consistent, i.e., data products from Landsat and MODIS should be highly correlated and comparable 336 in both time and space so that the temporal and spatial variability from two data sources can be 337 reasonably combined. We have chosen to fuse Landsat and MODIS surface reflectance products 
rather than derived vegetation indices because STARFM requires that the coarse resolution image can be linearly aggregated from a fine resolution image.

340 Prior to fusion, corrections are applied to the input imagery to maximize consistency and usability of Landsat-MODIS image pairs. Normalization of the MODIS daily directional surface reflectance to Nadir BRDF-adjusted Reflectance (NBAR) improves correlations with Landsat imagery, which are collected at near-nadir view angles (Gao et al., 2010; Feng et al., 2013). More precise co-registration of the MODIS and Landsat pair images is achieved through a pixelincremented shift procedure that maximizes spatial correlation.

After these corrections, it is useful to assess the consistency between input imagery used in a fusion experiment. This information can be valuable in interpreting unexpected behavior and apparent biases in the output timeseries. In this study, Landsat 5 TM, Landsat 7 ETM+, and Landsat 8 OLI surface reflectance were used. Landsat TM/ETM+ and MODIS surface reflectance has been examined in previous studies (Gao et al., 2006; Feng et al., 2013). Landsat 8 OLI bandwidths are slightly different from TM and ETM, which can lead to biases with respect to MODIS. To conduct the assessment, the Landsat and MODIS surface reflectances were first resampled to 960m spatial resolution for pixel-to-pixel comparison. An aggregate resolution, coarser than the native resolution of the MODIS reflectance products, was used in this comparison to reduce the effects of varying MODIS pixel footprint size with different view angles (Tan et al., 2006). For off-nadir views, the MODIS pixel becomes increasing elongated, and may encompass a different set of Landsat pixels depending on the view angle. Cloud masks from Landsat and MODIS surface reflectance products were used to exclude cloudy pixels. The remaining clear Landsat and MODIS pixels acquired from the same day were used to generate the statistics.

In addition, the fused Landsat-MODIS output surface reflectances and the derived NDVI were compared to actual Landsat observations that were not used in data fusion due to clouds or gaps. Only clear pixels from these actual Landsat observations were used for comparison at Landsat $30 \mathrm{~m}$ resolution.

\subsubsection{Selection of Landsat-MODIS Input Pairs}

365

The STARFM algorithm can use one or two input pairs of Landsat and MODIS images to predict a Landsat-like image on a MODIS date where a Landsat overpass is not available. In this study, we used the single-pair option because in a highly dynamic agricultural Midwestern landscape 
368 it is difficult to obtain two clear Landsat-MODIS image pairs with surface conditions reasonably

369 similar to the target retrieval date. Furthermore, variations in MODIS pixel footprint with viewing 370 angle can further degrade consistency between input and retrieval dates even under stable surface 371 conditions.

372 For the single-pair option, the fusion package has two automated approaches for assigning an 373 input MODIS-Landsat image pair to each prediction date within the targeted output timeframe. The two automatic options in the system include 1) choosing the image pair with the nearest date to the prediction date, or 2) using the image pair that has the highest spatial correlation with the MODIS image on the prediction date. In practice, spatial correlation coefficients are computed for MODIS images on all possible pair (Landsat overpass) and prediction dates. Then for each prediction date, the pair with the highest correlation is saved in pair selection table used in the fusion process. In general, this tends to produce similar results to option (1), but the temporal bounds of reconstruction governed by a given input image pair may shift somewhat based on rates of change in land-surface conditions. The temporal bounds developed through automated option (2) in this study are indicated as vertical bars in Fig. 2 .

383

\subsection{Extracting Phenology at Field Scale}

385 The final output NDVI time-series from the data fusion system combines the actual Landsat observations on Landsat overpass dates and the fused Landsat-MODIS data retrieved between Landsat overpasses. The phenology extraction process employed here used all clear pixels, identified using the Landsat cloud mask, from all available Landsat observations deemed either clear or partially clear.

390 Two established phenology approaches (TIMESAT and MODIS) were evaluated for both utility and ease of implementation. The TIMESAT program (Jonsson \& Ecklunch, 2004) provides eleven phenological metrics, including dates of start of growing season and end of growing season. The

393 TIMESAT software smoothes the NDVI data and fits them to a selected function, using either 394 asymmetric Gaussians, double logistic or Savitzky-Golay filters. The key phenological metrics start and end of the season - are identified as dates when the NDVI passes predefined thresholds, 
396 defined in terms of percentage of the seasonal amplitude (maximum value minus minimum base 397 value) in the NDVI. These thresholds need to be appropriately defined to capture the growth stages.

398 The MODIS phenology algorithm (Zhang et al., 2003) uses a piecewise logistic fitting function. 399 Time-series features that indicate the onset of green-up, the onset of maturity, the onset of 400 senescence, and the onset of dormancy are determined by the curvature of the logistic function. The 401 curvature of a smooth function measures how quickly a curve is changing at a given point. The 402 curvature approach does not require any pre-defined thresholds. For comparison to TIMESAT 403 phenological metrics and crop growth stages, only green-up dates (start of the season) and dormancy 404 dates (end of the season) were extracted in this study.

405 Both phenology approaches work better when more than one year of time-series data are 406 available. In our study area, crop rotation is a common practice and farmers normally plant different 407 408 crops (i.e. soybeans or corn) in two consecutive years. Including multiple years of remote sensing data may introduce uncertainties due to land cover changes. In order to generate crop phenology for a specific year (referred to as the "focus year"), we have extended each focus year of VI data to two years by padding with data from the same year. Data from the first half of the year were added after

411 the end of the focus year, while data from the second half of the year were inserted before the 412 beginning of the focus year. The padded time-series were only used for constructing time-series 413 functions. Only dates within the focus year were used to determine phenology dates and 414 phenological metrics.

415 The fitting functions in both phenology programs allow differential weighting of time-series data 416 at a given pixel. In this study, we assigned three classes of weights at the pixel level to represent 417 different data sources and quality. For the observed Landsat data, clear pixels were weighted as 1.0 418 (full contribution) while cloudy or missing pixels (e.g., due to the SLC failure on Landsat 7) were 419 assigned as 0.0 (no contribution). For the fused Landsat-MODIS data, the weights for the valid 420 pixels were assigned as 0.25 (reduced contribution). These weights were empirical estimates based 421 on the data quality and previous assessment (Gao et al., 2008). The MODIS phenology approach 422 was modified to use the same data smoothing and filtering preprocessing as used in the TIMESAT 423 program. Other information, such as land surface temperature used in the MODIS phenology 424 program, was not used in this study. These modifications were made to maximize similarity in 
425 inputs to both programs, and to better focus on evaluating the two phenology approaches themselves 426 (threshold vs. curvature).

427

\subsection{Linking Remote Sensing Phenology to Crop Growth Stages}

Crop phenology extracted from remote sensing data is an indirect estimate of physiological crop 430 growth stages, and is based on seasonal variations in greenness. To relate to crop growth stages, crop 431 phenology metrics obtained from the remote sensing data were assessed using ground observations 432 made in-field (Sec. 2.6) and as summarized at the county and district levels in the NASS crop 433 progress reports (Sec. 2.2). Crop progress reports average planting, fruiting, and harvesting progress 434 for crops within the reporting district. For corn, progress on the percentages of crops planted, 435 emerged, tasseled, silked, milk, doughing, dented, mature, and harvested are reported weekly (NASS 436 Terms, 2015). For soybean, weekly progress on the percentage of crops planted, emerged, bloomed, 437 setting pods, turning color, dropping leaves, and harvested are reported (Table 1). Since remote 438 sensing phenology dates are directly related to changes of crop greenness, this research focuses on retrieval of the growth stages that are most sensitive to remote sensing observations, such as the 440 green-up and dormancy dates. The green-up (or start of the season) dates were compared to the 441 reported crop emergence dates. The dormancy (or end of the season) dates were compared to the 442 mature dates (or leaf-dropping stage for soybean) and harvest dates. Comparisons were conducted 443 for corn and soybeans separately. The median dates of green-up and dormancy for each county and 444 for the "central Iowa" district were extracted and compared to the median dates of crop growth 445 stages from the NASS crop progress reports. In addition, as a spot check on general reasonability of 446 the fused NDVI time-series reconstruction, we compared retrieved NDVI with NEE/GPP curves 447 derived from flux measurements at the tower sites described in Sec. 2.5. Qualitative agreement in 448 timing between these independent measures of crop productivity adds some additional confidence 449 that the fusion is providing reasonable temporal information. 


\section{RESULTS AND ANALYSIS}

452 The data fusion results and crop phenology were analyzed using the entire Landsat scene (path 45326 and row 31), which covers central Iowa. Some results are demonstrated for the subset area (Fig. 454 1) around South Fork, Iowa for better visualization.

\subsection{Landsat-MODIS Fusion Results}

\subsubsection{Input Data Consistency between Landsat and MODIS}

458

459

460

461

462

463

464

465

466

467

468

469

470

471

472

473

474

475

476

477

478

479

As mentioned above, the level of consistency between Landsat and MODIS reflectance inputs can affect the accuracy of the data fusion results. Therefore, assessment of temporal and intrasensor biases can provide valuable information for interpreting performance in the output time series. Using the 960-m aggregated reflectance datasets described in Sec. 3.1.1, the differences between Landsat and MODIS daily NBAR on average over all years for the study site were within +-0.012 for the red band and within +-0.025 for the NIR band. The mean absolute differences were less than 0.015 and 0.030 for the red and NIR bands, respectively. The $\mathrm{R}^{2}$ for all years were above 0.73 for the red band and above 0.86 for the NIR band.

Although Landsat shows good agreement with MODIS surface reflectance products, the agreement varies among Landsat sensors due to differences in sensor characteristics (e.g. sensor bandwidths, band response functions), satellite orbit (e.g. solar and viewing angles), and data processing approach (e.g. calibration and atmospheric correction). Landsat-7 ETM+ surface reflectances show small biases and mean absolute differences, as well as higher $\mathrm{R}^{2}$, in comparison with Terra MODIS data. This is likely because the Landsat 7 and Terra satellites are in the same orbit, and the overlap swath is collected at similar view angles, near nadir. Furthermore, MODIS geolocation accuracy is best at nadir view. The newer Landsat-8 OLI sensor has a narrow bandwidth in the NIR, similar to that on MODIS, giving significantly smaller mean differences between OLI and MODIS for the NIR band in 2013 and 2014 in comparison with ETM+. However, OLI-MODIS mean absolute differences (MAD) were larger and $\mathrm{R}^{2}$ were smaller, and this was likely due to view angle effects. The MODIS observations on the Landsat 5 and 8 acquisition dates were mostly collected from off-nadir viewing angles. Even though the angular effect on BRDF has been corrected in this study, the footprint of a given MODIS pixel is much larger at a large off-nadir view 
480 (Tan et al., 2006). The aggregated Landsat and MODIS pixels at off-nadir view may not match 481 exactly. In addition, differences in aerosol information used in the Landsat and MODIS atmospheric 482 corrections may introduce some dissimilarity in the resulting surface reflectance products (Vermote 483 et al. 2002; Masek et al., 2006).

484 The STARFM data fusion approach takes into account time invariant differences in reflectance 485 between Landsat and MODIS. In theory, a systematic bias between Landsat and MODIS for the 486 prediction period does not affect data fusion results since the STARFM model uses the difference of 487 reflectance in the prediction. However, if biases vary during the prediction period, these variations 488 can affect the fusion results. Fig. 4 shows the variation in bias (Landsat minus MODIS) for the red 489 and NIR bands between pair images for each year. Landsat 8 OLI data are plotted separately for the evaluation. Consistent time-series Landsat-MODIS fusion results can be expected if Landsat and 491 MODIS pair images show consistent biases (flat line) during the year. In Fig. 4, the NIR band shows 492 higher variation in bias than the red band especially during growing season, which may be due to the 493 higher reflectance in the NIR band during the growing season. Landsat-8 OLI data in 2014 show 494 smaller variations in bias during the growing season. More reliable fusion results for OLI surface 495 reflectances can be expected in this case. Note that even though Landsat 5 and 7 reflectances for 496 most years were consistently higher in the red band and lower in the NIR band, these systematic 497 biases will not affect the STARFM fusion results. Only the time variation in these biases will be 498 problematic. 


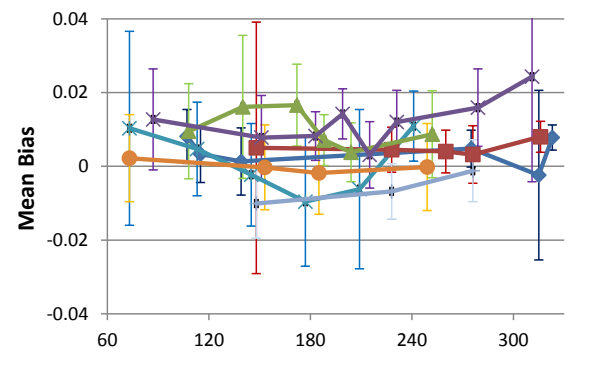

(a) Landsat 5/7 - MODIS, red

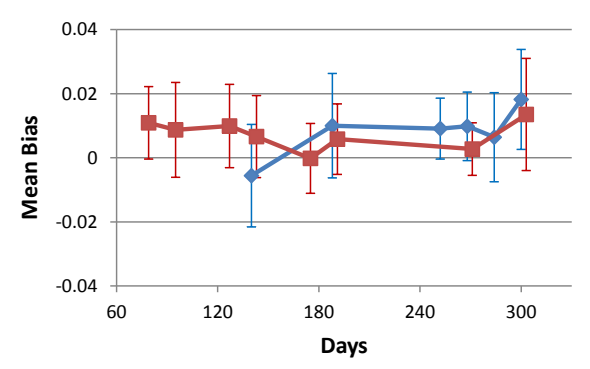

(c) Landsat 8 OLI - MODIS, red
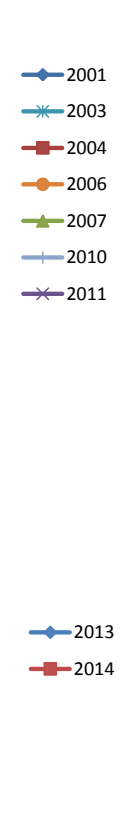

499

500

501

502

503

504

505

506

507

508

509

510

511

512

513

514

515

\subsubsection{Assessment of fused Landsat-MODIS Reflectances}

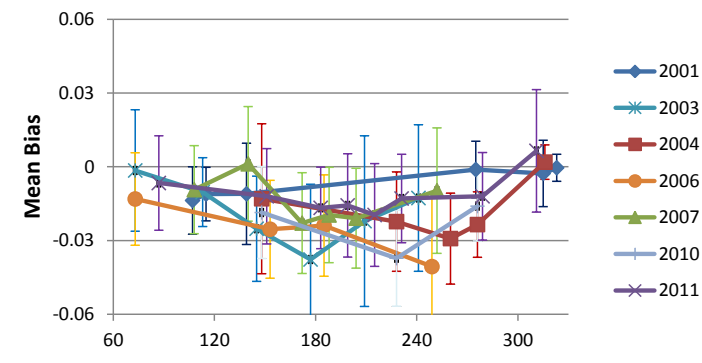

(b) Landsat 5/7 - MODIS, NIR

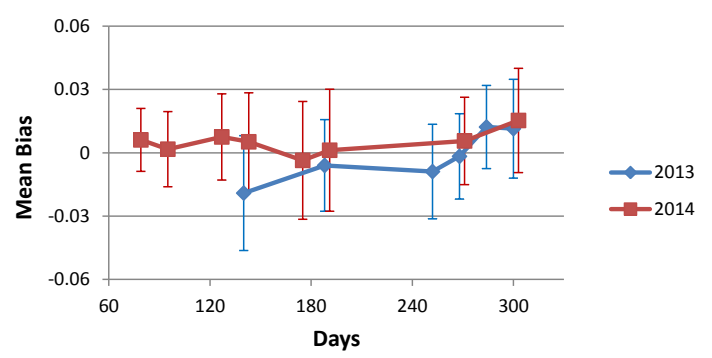

(d) Landsat 8 OLI - MODIS, NIR

Fig. 4. Mean bias (lines) and standard deviation (bars) between Landsat surface reflectance and MODIS daily NBAR for the red and NIR bands in pair images for each year of the study. A consistent bias through time will not affect fusion results, while variation in bias will.

Nine years of the fused Landsat-MODIS surface reflectances at 30m resolution were generated for central Iowa. The accuracy of the Landsat-scale reflectance predictions at 30-m resolution was assessed by comparing fused Landsat-MODIS reflectances and actual Landsat observations that were not used in the data fusion process (observations plotted below the horizontal lines in Fig. 2). These Landsat images include partially cloudy scenes and ETM+ images affected by the SLC failure. All cloudy and invalid pixels were excluded from comparison. Table 2 shows statistics from this inter-comparison, using all unused Landsat images available in a given year as the basis for comparison. The mean biases were within +-0.01 for the red band and within +-0.02 for the NIR band. The 2007 and 2011 show higher negative biases (-0.008 and -0.004) in the red band, which are due in part to the large variation in biases between Landsat and MODIS pair images for these two years (Fig. 4a). Similarly the high positive biases in the NIR band for 2004 and 2006 (0.018 and 0.016) were partially caused by a large temporal variation in MODIS-Landsat bias (Fig. 4b). The 
516 root-mean-square difference (RMSD) for 2013 and 2014 between fused and observed NIR band

517 reflectances were slightly higher than for the rest of the years since OLI images were primarily used

518 as pair images while all ETM+ images were used to assess the fusion results. The difference

519 between OLI and ETM+ surface reflectance may partially contribute to this higher variation. For all

520 years, the correlations $\left(\mathrm{R}^{2}\right)$ between the fused Landsat-MODIS data and actual Landsat observations

521 were above 0.54 and 0.65 for the red and NIR bands, respectively. The mean absolute differences

522 (MAD) were within 0.026 for the red band and 0.053 for the NIR band.

523

524 Table 2. Mean bias (MB), root-mean-square difference (RMSD), mean absolute difference (MAD) 525 and $\mathrm{R}^{2}$ computed at 30-m resolution between the fused Landsat-MODIS data and actual Landsat 526 observations not used as input to the data fusion due to gaps or clouds (i.e., dots below the horizontal 527 lines in Fig. 2).

\begin{tabular}{c|cccc|cccc}
\hline & \multicolumn{4}{|c|}{ Red } & \multicolumn{4}{c}{ NIR } \\
\hline Year & MB & RMSD & MAD & $\mathrm{R}^{2}$ & MB & RMSD & MAD & $\mathrm{R}^{2}$ \\
\hline 2001 & -0.001 & 0.024 & 0.017 & 0.637 & -0.004 & 0.059 & 0.044 & 0.731 \\
2003 & -0.003 & 0.026 & 0.018 & 0.674 & 0.001 & 0.056 & 0.037 & 0.735 \\
2004 & 0.001 & 0.030 & 0.020 & 0.601 & 0.018 & 0.058 & 0.045 & 0.739 \\
2006 & 0.004 & 0.029 & 0.020 & 0.646 & 0.016 & 0.052 & 0.040 & 0.707 \\
2007 & -0.008 & 0.025 & 0.017 & 0.713 & -0.003 & 0.063 & 0.035 & 0.702 \\
2010 & 0.000 & 0.033 & 0.022 & 0.619 & -0.003 & 0.060 & 0.044 & 0.656 \\
2011 & -0.004 & 0.023 & 0.016 & 0.791 & 0.008 & 0.050 & 0.038 & 0.769 \\
2013 & 0.004 & 0.036 & 0.026 & 0.540 & 0.013 & 0.063 & 0.047 & 0.664 \\
2014 & -0.002 & 0.028 & 0.019 & 0.636 & 0.012 & 0.073 & 0.053 & 0.656 \\
\hline
\end{tabular}

528

529

$530 \quad$ 4.1.3 NDVI Time-series

531 Daily NDVI images at 30-m resolution were computed using the fused surface reflectances. Fig. 5325 shows a subset of NDVI images extracted every half month from early April to middle October in 533 2011, along with the CDL classifications for 2011 in the lower right. Clear seasonal trends in NDVI 
534 for crops and natural vegetation can be identified at these field scales. Deciduous forest (northeast

535 part of the subset) shows higher NDVI and earlier green-up than do crop pixels. Most of the

536 vegetated pixels reach maximum NDVI in early August. Corn and soybean crops senesce in early to

537 middle October. These fields can be clearly recognized in the early and late growing season, in

538 contrast to the forested pixels.

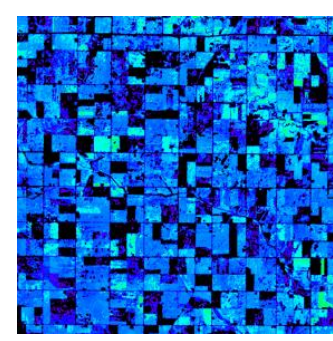

April $1(91)$

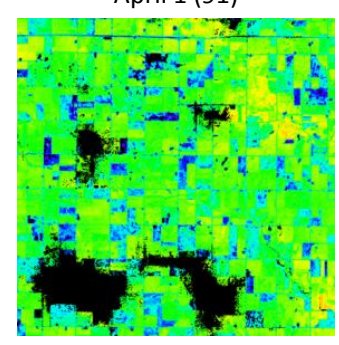

June 15 (166)

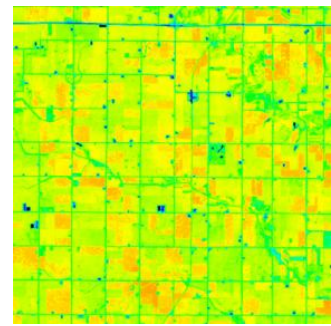

September 1 (244)

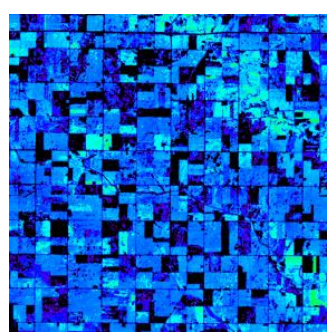

April 15 (105)

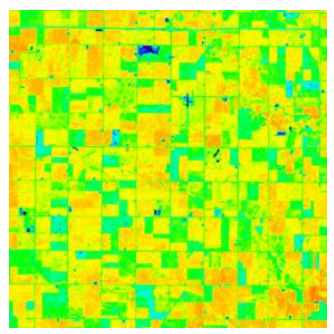

July 1 (182)

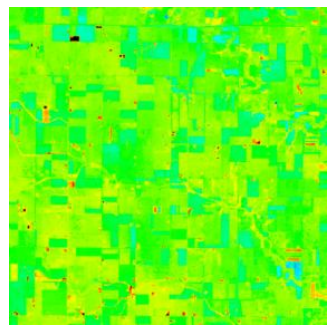

September 15 (258)

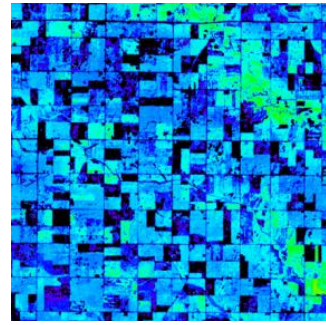

May 1 (121)

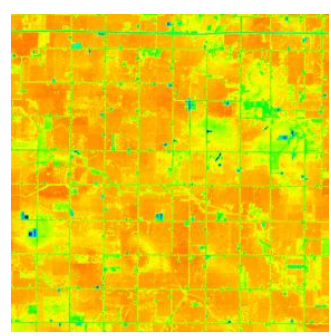

July 15 (196)

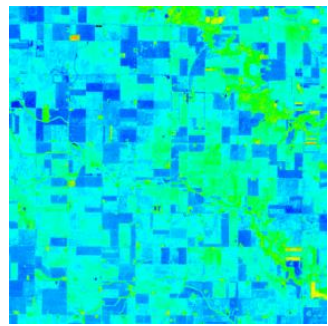

October 1 (274)

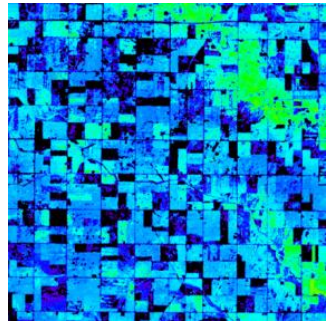

May 15 (135)

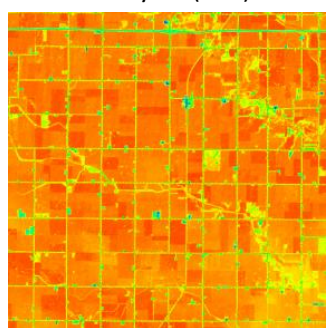

August 1 (213)

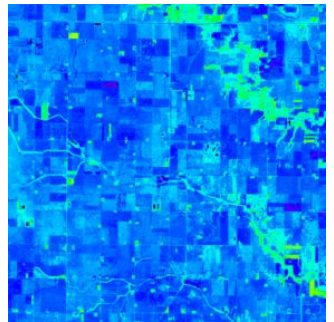

October 15 (288)

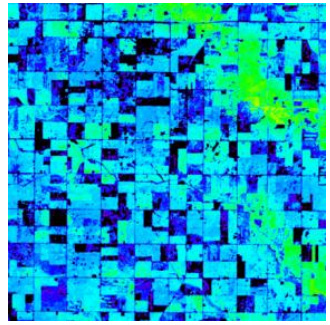

June 1 (152)

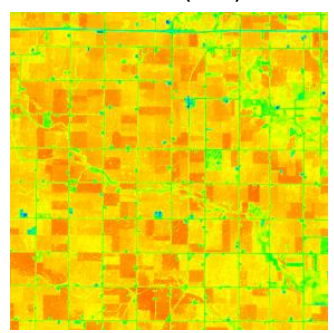

August 15 (227)

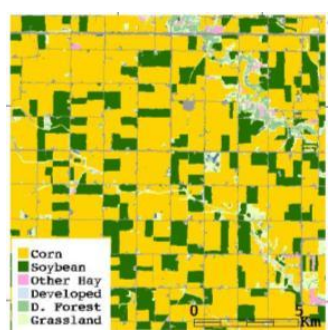

539

540

541 Fig. 5. NDVI time-series computed from the fused Landsat-MODIS surface reflectances for a subset area (South Folk, Iowa) from April 1 to October 15, 2011 (black pixels in the June 15 image are missing values due to cloud contamination in the MODIS image for that day).

To compare temporal patterns in the fused datasets at the 30-m pixel level, time-series NDVI were extracted for three representative pixels (corn, soybean, and forest) during the growing season. 
548 fitting curves using a double logistic function. The corn and soybean samples were selected from the 549 two flux tower sites in South Fork, Iowa, while the forest sample was taken from an area near the 550 tower sites. Each class shows a distinct temporal pattern in NDVI evolution. The forest pixel 551 greens-up early, reaches maximum NDVI in early spring, and shows high NDVI values in

552 September and even in October images. Among the cropped pixels, corn NDVI increases earlier 553 than soybean and both crops reach maximum NDVI in late July to early August. The contrast in 554 NDVI between land cover types is most pronounced during the spring, which suggests that the 555 spring images are more appropriate for land cover and crop type classification if only red and NIR 556 bands are available or used. During the summer, the corn sample shows a longer plateau near 557 maximum NDVI - corn greens up earlier than soybean and senesces later, consistent with a longer 558 growing period. The NDVI for the soybean sample decreased more quickly than the corn and forest 559 samples during the fall.

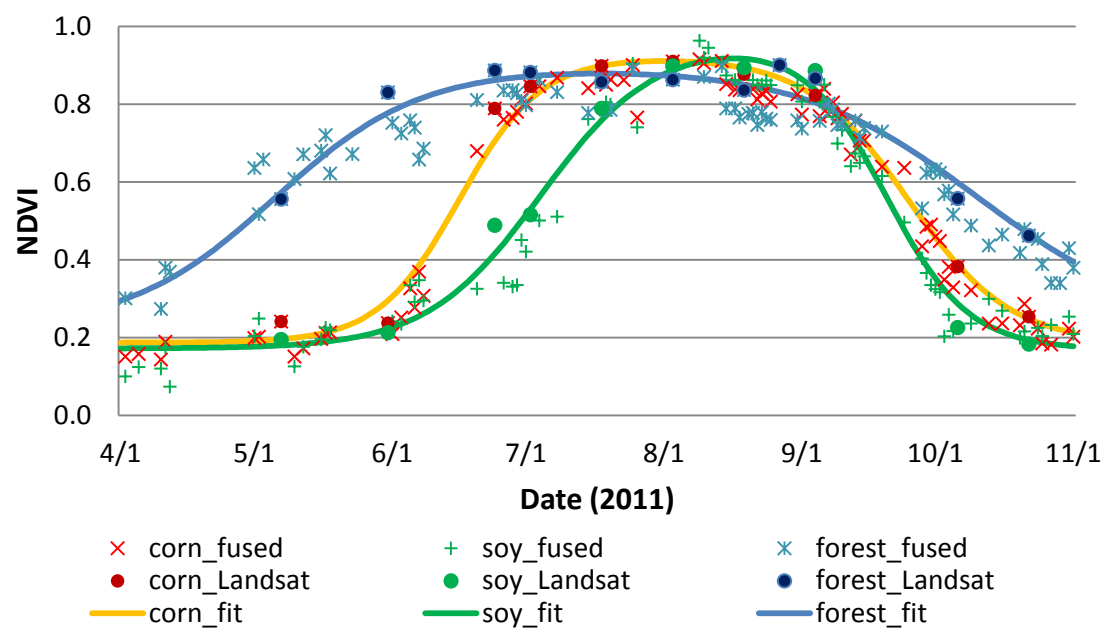
Fig. 6. Corn, soybean and forest (near tower site) pixels show different temporal patterns of NDVI 562 from early April to late October in 2011. Both the fused Landsat-MODIS data and actual Landsat observations (dots) were used to construct fitting curves using a double logistic function (lines).

Similar to the reflectance comparisons discussed in Sec. 4.1.2, NDVI derived from the fused Landsat-MODIS surface reflectances at 30-m pixel resolution were compared to Landsat data that were not used as input to the data fusion process. Table 3 shows the mean bias, RMSD, mean absolute difference and $\mathrm{R}^{2}$ for the fused and observed NDVI data at 30-m resolution. Biases in 
570 NDVI for all years are in the range of -0.011 to 0.028 . All years show high correlations $\left(R^{2}>0.8\right)$.

571 The mean absolute differences (MAD) in NDVI are less than 0.083 for all years. The high positive

572 NDVI biases for 2007 and 2011 are due to the larger negative biases in the red band, while the high

573 positive NDVI bias in 2004 is due to the large positive bias in the NIR band (see Table 2).

574

575 Table 3. Mean bias (MB), root-mean-square difference (RMSD), mean absolute difference (MAD)

576 and $\mathrm{R}^{2}$ between NDVI derived from the fused Landsat-MODIS reflectance and the actual Landsat

577 observations (not used in data fusion) based on 30-m resolution pixels for each year.

578

\begin{tabular}{c|cccc}
\hline Year & MB & RMSD & MAD & $\mathrm{R}^{2}$ \\
\hline 2001 & -0.004 & 0.098 & 0.072 & 0.856 \\
2003 & 0.010 & 0.093 & 0.064 & 0.879 \\
2004 & 0.021 & 0.115 & 0.083 & 0.801 \\
2006 & 0.006 & 0.108 & 0.078 & 0.817 \\
2007 & 0.027 & 0.095 & 0.068 & 0.815 \\
2010 & -0.011 & 0.107 & 0.077 & 0.826 \\
2011 & 0.028 & 0.083 & 0.066 & 0.896 \\
2013 & 0.006 & 0.103 & 0.077 & 0.844 \\
2014 & 0.011 & 0.097 & 0.071 & 0.846 \\
\hline
\end{tabular}

579

580

581

\subsection{Crop Phenology at Field Scale}

582

\subsubsection{Phenology from Remote Sensing Approaches}

583

Two approaches (MODIS and TIMESAT) were applied to extract crop phenology from the

584 daily time-series NDVI. The TIMESAT approach relies on a pre-defined threshold (percent change

585 of the seasonal amplitude between minimum and maximum NDVI values) to determine the start of

586 the season, the end of the season, and the length of the season. The MODIS phenology approach 587 uses curvature analyses to identify inflection points in the fitting curve. In this study, a double logistic function was selected to fit time-series NDVI for both approaches.

589

Fig. 7 shows the green-up dates detected using different thresholds (TIMESAT) and the 590 curvature approach (MODIS) for 2011 and 2014. For comparison with CP report data, which

591 represent cumulative percentages of growth stages, the remote sensing green-up dates (or the start of 592 the season) were also plotted as cumulative percentages generated from the distribution of pixels 
across the entire Landsat scene. The crop growth stages were extracted from the NASS CP reports at

594 the district level for central Iowa. Reporters observe and report on crop emergence as soon as plants 595 are visible, but this early stage was not detectable from spaceborne observations of NDVI. 596 Therefore, the remotely sensed green-up dates were later than the reported emerged dates.

In Fig. 7, the reported emergence dates for corn are close to the green-up date produced using 598 a 10\% threshold in TIMESAT, while the emergence dates for soybean were closer to the predicted dates using a $15 \%$ threshold. The TIMESAT program sets the default threshold at $20 \%$, which produced results close to the MODIS curvature approach in the study area. A smaller threshold can generate earlier green-up dates, but it is also sensitive to noise and small variations in time-series NDVI and thus less reliable. The MODIS curvature approach produces more consistent green-up dates for both corn and soybean.

The best time to plant corn in Iowa, on average, is from late April to early May. Soybeans are usually planted one to two weeks later than corn. As published in the CP reports, 9\% of corn in central Iowa was planted by May 1, 2011 and 78\% by May 8, 2011, while 14\% of soybeans was planted by May 8 and $62 \%$ by May 15. In other words, soybeans were planted a week later than corn. The median reported corn emergence dates (at 50\% cumulative histogram level) in the CP reports were 9-10 days ahead of soybeans for both 2011 and 2014. The median corn green-up dates were 8-9 days ahead of the soybeans from the MODIS curvature approach, which was consistent with the $\mathrm{CP}$ reports. However, the threshold approach produced different results varying from 2 to

61210 days at 10\%, 15\%,20\% and 25\% thresholds (th_10, th_15, th_20, and th_25 in Figure 7). With a $61325 \%$ threshold, the TIMESAT approach produced similar green-up dates to the MODIS curvature 614 approach for soybeans but later green-up dates for corn. This implies that different thresholds may 615 be needed for different crops in order to compare to the emergence dates in the CP reports. In 616 addition, the green-up dates from TIMESAT also depend on the amplitude between minimum and 617 maximum NDVI values. This requires clear Landsat/MODIS observations around the peak growing 618 season in order to obtain reliable maximum NDVI. From a practical standpoint, the MODIS 619 curvature approach produced more consistent green-up dates for corn and soybeans. This feature is 620 important for building a standard procedure to map crop phenology. The curvature approach does 621 not require a pre-determined threshold and green-up dates only depend on the observations during 622 the early growing season, thereby enhancing utility for realtime applications. The phenology dates 
623 were more consistent for corn and soybeans. For these reasons, the MODIS curvature approach is 624 used in the remainder of this paper to map crop phenology and to assess connections with 625 physiological crop growth stages.

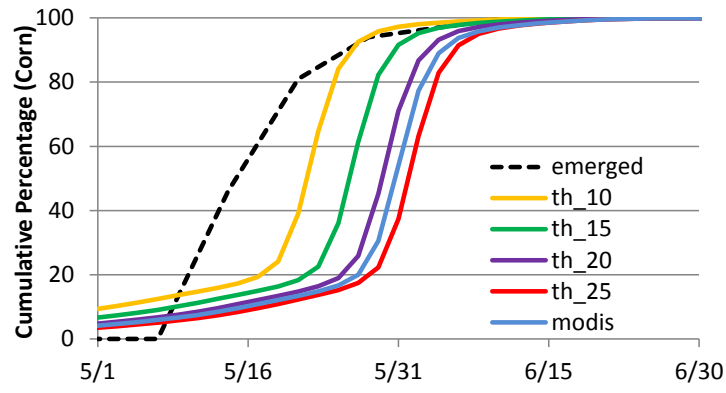

(a) Corn, 2011

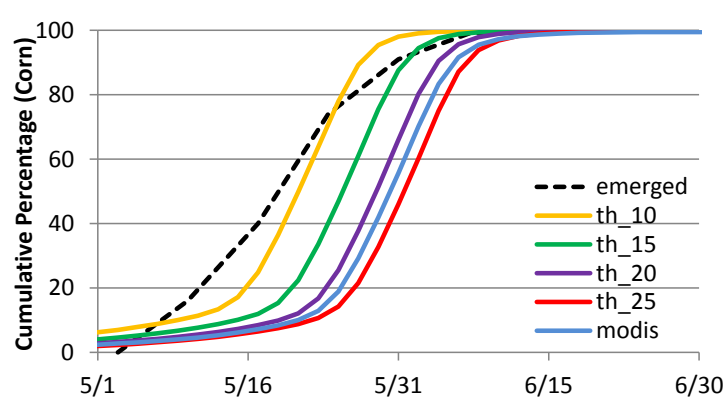

(c) Corn, 2014

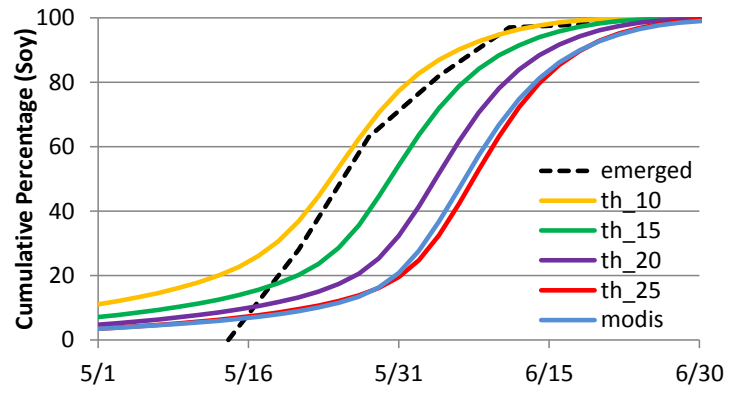

(b) Soybean, 2011

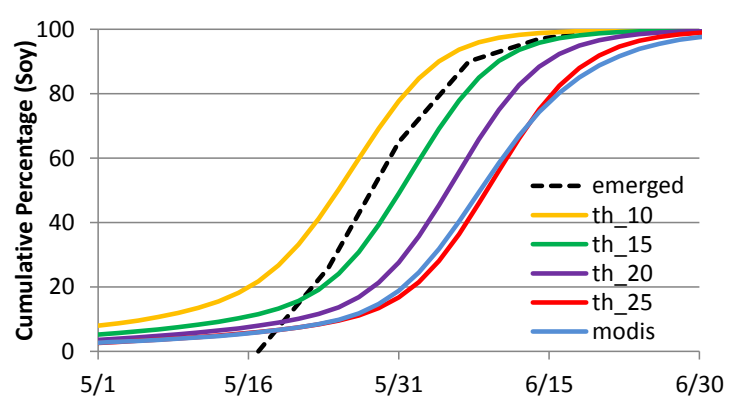

(d) Soybean, 2014
626

627

628

629

630

631

632

633

634

635

636

637

638

639

Fig. 7. Green-up (or the start of the season) dates from different phenology approaches and the percent emergence (dashed lines) reported in the CP reports for central Iowa in 2011 and 2014 show different relationships. The MODIS curvature approach (blue lines) predicts later green-up dates than the $\mathrm{CP}$ emergence observations, but the differences of green-up dates between corn and soybeans were relatively stable. The TIMESAT threshold approach using different threshold levels $(10 \%, 15 \%, 20 \%$, and $25 \%)$ shows variations in the green-up dates between corn and soybeans.

\subsubsection{Mapping Phenology at Field Scale}

Crop phenology detected from remote sensing data provides valuable information about field-to-field spatial variability in crop development over agricultural landscapes. Fig. 8 illustrates green-up and dormancy dates for the selected years from 2001 to 2014, zooming into a subset area in South Fork, Iowa. Corn and soybeans show clearly different green-up dates. For all years, corn 
640 showed earlier green-up than soybean as revealed in histograms of green-up dates (second row in 641 Fig. 8). Green-up dates for corn in 2006 were earlier than for the other three years, likely due to the 642 early favorable conditions (warmer than average and dry enough for machinery operation in 2006 643 around the local area) for seedling development. In 2011, corn green-up dates were distributed over 644 a relatively shorter period of time around early June, with some overlap with green-up time for 645 soybean crops. While variability in dormancy dates between fields is apparent, the differences in 646 dormancy dates were not as obvious as differences in green-up dates between the two crops (see 647 histograms in Fig. 8). In 2006, peak dormancy dates for corn occurred slightly earlier than for 648 soybean, while the opposite relative timing is inferred in 2011. In 2001 and 2014, dormancy dates 649 for the two crops were very close. Forest pixels always showed an earlier green-up date and a later 650 dormancy date, as exemplified by the individual forest sample in Fig. 6. 

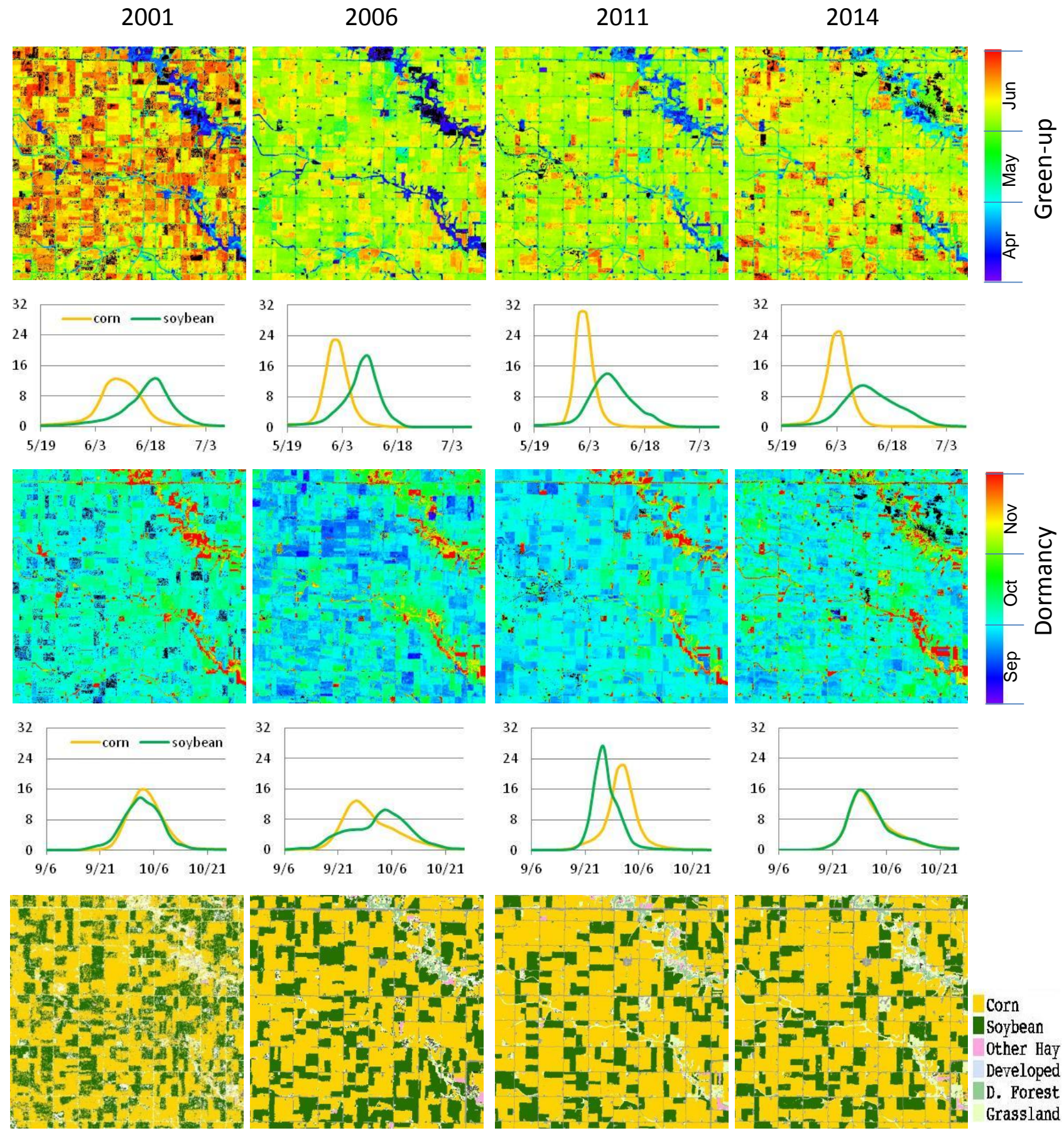

652 Fig. 8. Green-up and dormancy dates detected from the fused Landsat-MODIS data for 2001, 2006, 653 2011, and 2014. Top two rows show green-up dates (April to June) and histograms of green-up dates 654 for corn (yellow) and soybean (green), the next two rows show dormancy dates (September to 655 October) and histograms. Bottom row shows the CDL for the corresponding years in each column. 


\subsection{Phenology and Crop Progress Stages}

658 Crop phenology metrics retrieved from the fused Landsat-MODIS data were compared to crop 659 growth stages reported at district and county levels from the NASS CP reports. Observations at the 660 field scale were examined using the corresponding Landsat pixels.

\section{4.3.1 Comparison at Tower Sites}

662

Fig. 9 shows the fitted NDVI curves from 2011 for corn and soybean pixels at the two South 663 Fork flux tower sites, overlaid with the crop growth stages from NASS county-level CP reports. 664 Also shown are daily NEE and GPP estimates derived from eddy covariance measurements during 665 the growing season in 2011. The general correspondence in the time behavior of the NDVI and crop 666 carbon uptake curves demonstrates that the NDVI time-series appears to be behaving reasonably in 667 these two fields in relationship with the NASS CP stages.

668 In the early growing season, NDVI was around 0.2 in both fields during the county-average 669 planting time. NDVI increased significantly after the NASS-reported emergence date, and close to 670 the time net carbon uptake by the plant canopy is indicated in the flux measurements. Both NDVI 671 and NEE/GPP reach maximum values around the same time - in the silking stage for corn and after 672 pod-setting for soybean. NEE and GPP were almost linearly related to NDVI during the vegetative 673 stages. The period of peak NDVI was shorter for soybean than for the corn site. Daily NEE/GPP 674 entered decline around the time that NDVI started to decrease in each field, indicating a conversion 675 of green to senesced biomass. NEE reached zero around the mature stage for corn and the leaf-drop 676 stage for soybean. After the crops were harvested, NDVI values for both corn and soybean plots 677 were restored to the pre-season values. Even though the crop growth stages were extracted from the 678 NASS county level report and may not necessarily be expected to perfectly match conditions at the 679 Fluxnet sites, Fig. 9 still shows clear correlations between NDVI time-series at 30-m resolution and 680 specific crop growth stages observed on the ground. 


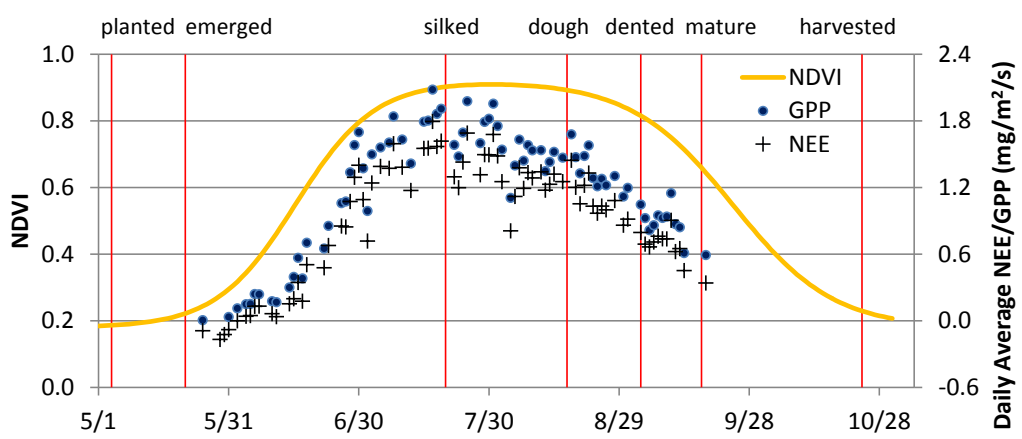

(a) Corn

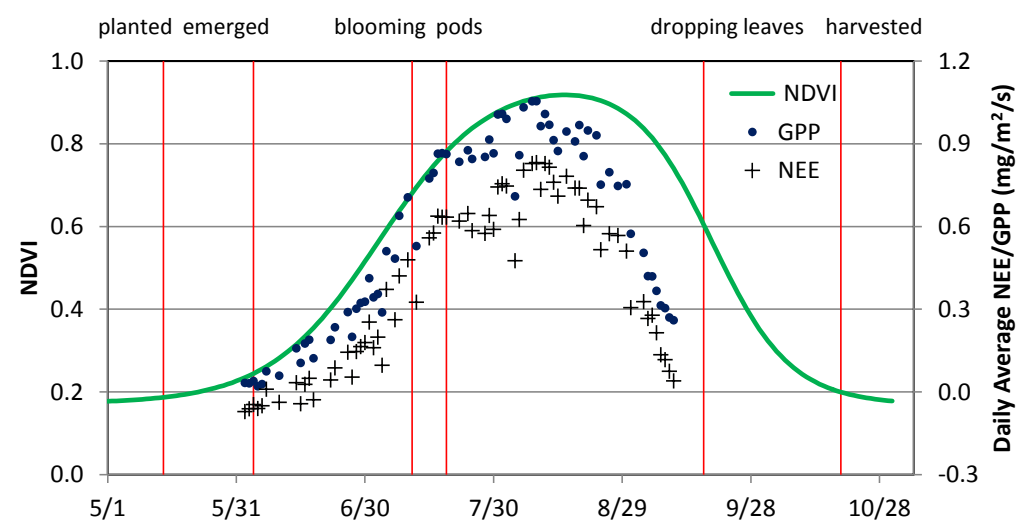

681

682 Fig. 9. NDVI curves for corn (a) and soybean (b) pixels compared to daily NEE and GPP (secondary 683 axis, only measured during vegetative growing season) and crop growth stages from NASS county684 level reports in 2011 (red vertical lines). Clear correspondences can be identified among time-series 685 686 NDVI, NEE and GPP during crop vegetative stages at the Landsat pixel resolution.

\subsubsection{Comparison at District Level}

As an example of performance at the district scale, Fig. 10 shows cumulative histograms of remotely sensed phenology metrics in comparison with growth stages reported by NASS for the "central Iowa" district in 2011. In this example, green-up dates retrieved from remote sensing data were consistently later than the reported emergence dates. The mid-season (peak NDVI) dates retrieved from the remote sensing data were between the silking and doughing stages for corn and close to the pod-setting stages for soybean. The dormancy (end of the season) dates were slightly ahead of the reported harvest time for both crops. The dormancy stage describes the date that the change of leaf color or leaf drop were most significant. The dormancy stage for corn was detected 
696 after corn reached the mature stage when there was no green foliage present. For soybeans, the 697 dormancy stage was detected after the leaf dropping stage. The fact that reported harvest dates 698 occurred after the remotely sensed dormancy dates suggests that typical crop harvest dates could be 699 predicted or estimated using remote sensing, keying off the retrieved dormancy dates. This could be 700 useful both for management activities and for retrospective crop modeling efforts.

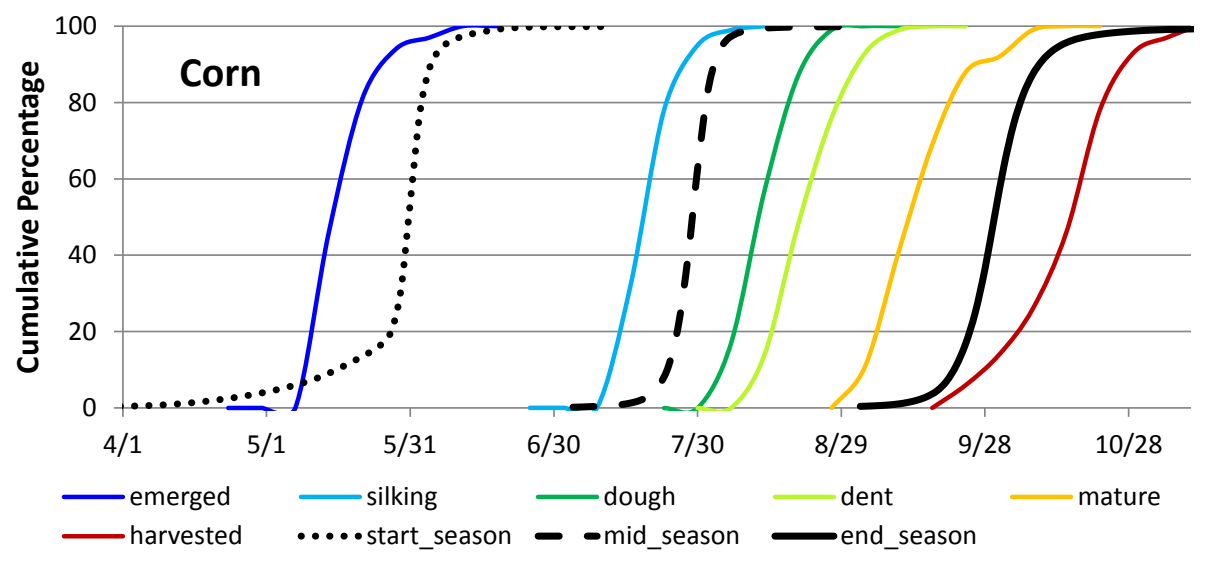

(a) Corn

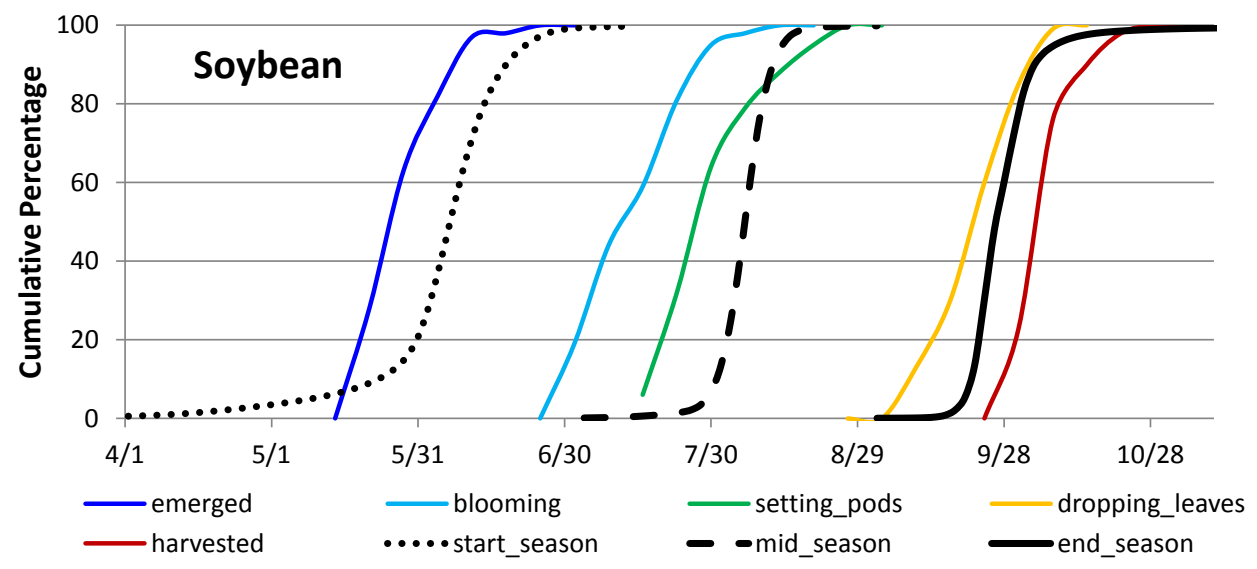

701

(b) Soybean

702 Fig. 10. Phenology dates detected from the fused Landsat-MODIS data (colored curves) and crop 703 growth stages reported in the NASS CP reports (dotted, dashed and solid black lines) at district level 704 for central Iowa in 2011.

705

706 These temporal relationships between the remotely sensed phenology metrics and NASS 707 reported crop stages were relatively stable across the years analyzed, when both the remote sensing 708 and NASS reports were available (2010, 2011, 2013 and 2014). Fig. 11 shows scatter plots of 
median values (at 50\% cumulative percentage) for green-up and dormancy dates for both corn and

710 soybeans in comparison with NASS-reported emergence and harvest dates. The scatter plots show a 711 strong linear correlation between the green-up dates and the emergence dates $\left(R^{2}=0.83\right)$ for both 712 corn and soybeans. Green-up dates were later than the emergence dates as noted above. Green-up 713 dates at the pixel level were compared to the field observations at a corn site (41.644N, 94.154W) 714 and a soybean site (41.644N, 94.145W) in Dallas County, Iowa in 2010 (see Section 2.6). The 715 remotely sensed green-up dates at were on May 31 and June 13 for the corn and soybean sites, 716 respectively. On these dates, the field observations indicate that both crops were primarily in the V3 stage, with plants exhibit 2-4 leaves. The V3 stage normally occurs 2-3 weeks after emergence.

A comparison of dormancy and harvest dates reveals somewhat different relationships for corn and soybeans. Corn was harvested within 2-3 weeks and soybeans within 1-2 weeks after dormancy dates were detected via remote sensing, as indicated by rapid changes in NDVI (green vegetation) during the end of the season. The 2010 field observations in Dallas County, Iowa also revealed a similar finding at the Landsat pixel resolution. For the corn site, the mature stage was first reported on September 11, the dormancy date was detected on September 17 and the harvest date was after September 25 (last reported mature date). For the soybean site, the mature stage was first reached on September 17, the dormancy date was detected on September 23 and the harvest date was after September 26 (last reported mature date). Soybeans need to be harvested within a short period of time after leaves drop to avoid pre-harvest loss. This may be a reason why harvest dates for soybeans were closer to the dormancy dates from remote sensing. 


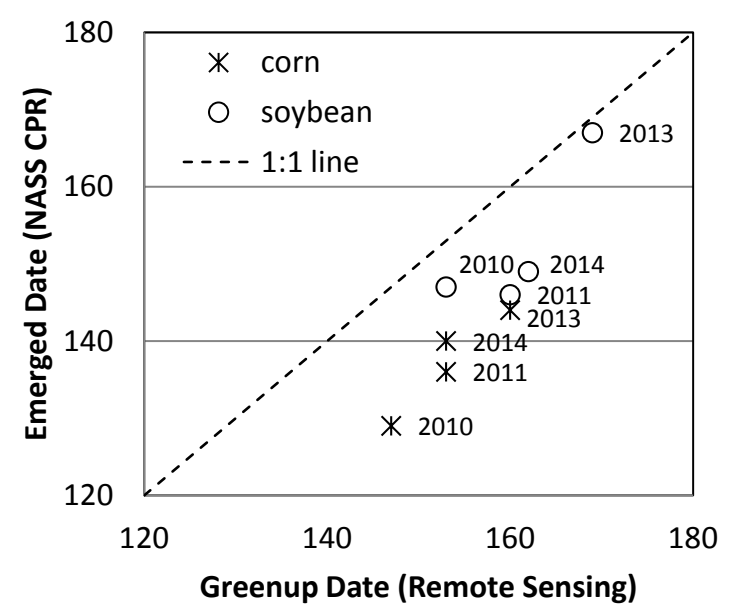

(a) green-up vs. emergence

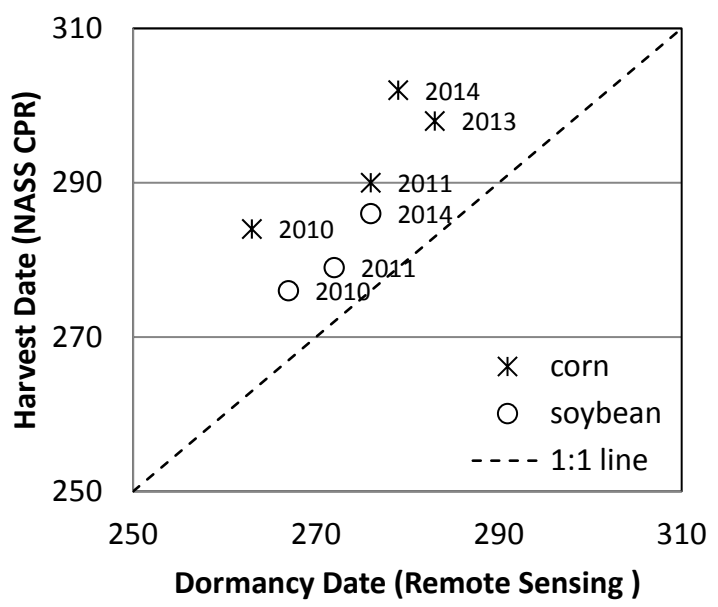

(b) dormancy vs. harvest
729

730

731

732

733

734

735

736

737

738

739

740

741

742

743

744

745

746

747

748

Fig. 11. Crop phenology (green-up and dormancy dates) detected using the fused Landsat and MODIS data compared to the crop progress stages (emergence and harvest dates) reported in the NASS CP reports in central Iowa (district level) for 2010, 2011, 2013 and 2014 (soybean harvest dates in 2013 were not available for central Iowa in the report).

In Fig. 12, these district-level comparisons are extended over the full set of years analyzed. For better illustration, the range on the two y-axes for each plot has been adjusted to optimize alignment, using the linear relationships between crop phenology and growth stages shown in Fig. 11. Even though the NASS CP reports were summarized based on sparsely distributed field surveys, a general agreement of trend between remote sensing phenology and the NASS CP data can be observed (see also Fig. 11). The remote sensing phenology captures the later green-up in 2013 observed by NASS reporters on the ground for both corn and soybeans. The offset in green-up between corn and soybean detected by the remote sensing is relatively uniform back through years prior to the NASS CP reporting era (before 2011). The late green-up dates in 2007 were likely due to wet conditions in early spring, as farmers were forced to wait for drier weather (NASS Bulletin, 2007). While corn green-up always preceded soybean, relative remote sensing dormancy dates for corn and soybean varied from year to year (also illustrated in Fig. 8). Even though harvesting date for individual fields depends on numerous non-biotic factors, including human resources, weather and marketing decisions, there are general correlations between remote sensing dormancy dates and 
749 observed harvest dates for corn and soybeans. The trend observed in recent years (2010-2014) 750 demonstrates a potential to forecast "expected" harvest dates for corn and soybeans after dormancy 751 is detected via remote sensing. In 2014, the soybean and corn harvests were 1-2 weeks behind 752 normal schedule due to a rain delay. As shown in Fig. 11, the harvest dates for individual fields may 753 be forecasted 1-3 weeks ahead of harvest operation.

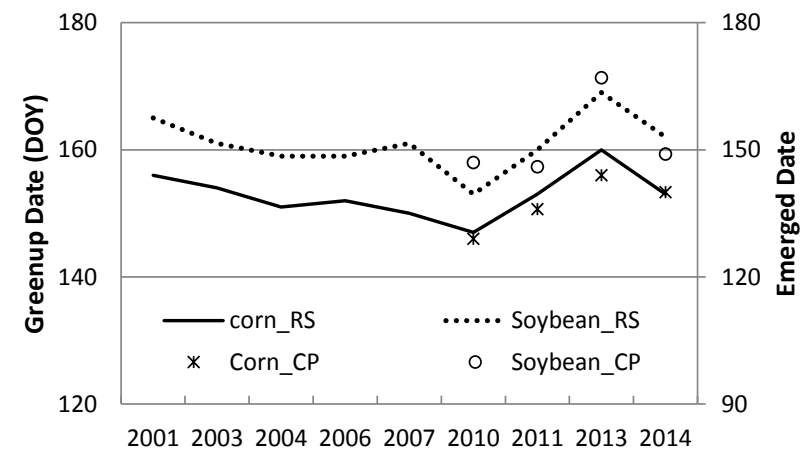

(a) green-up

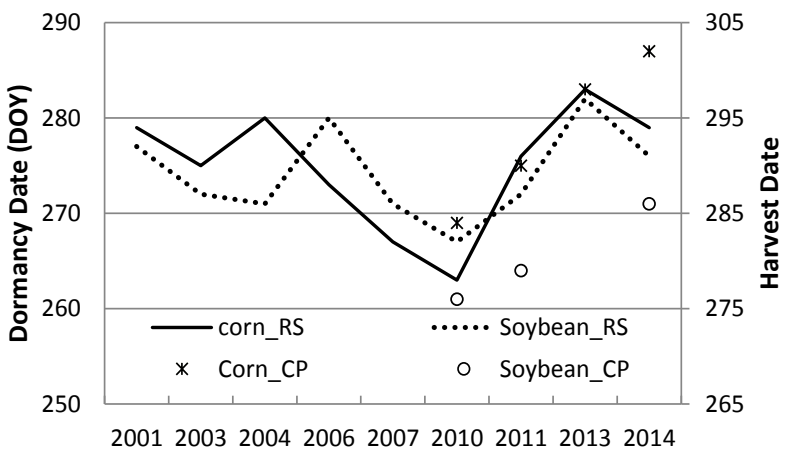

(b) dormancy

754

755 Fig. 12. Crop phenology (primary axis) detected using the fused Landsat-MODIS remote sensing 756 data (RS) in processed years from 2001 to 2014 overlaid with the crop growth stages (secondary 757 axis, difference range of dates) from the district-level NASS CP reports for central Iowa (available 758 2010 to 2014).

759

760

\subsubsection{Comparison at County Level}

761 The county-level information provided by NASS for 2010 and 2011 allows an assessment of 762 fused NDVI time-series performance at finer (sub-district) scales of spatial aggregation. Figure

76313 compares remote sensing and NASS crop growth stages for corn and soybean from 17

764 individual counties that were completely covered by the processed Landsat scene (Fig 1).

765 Counties are not identified by name to comply with the NASS privacy agreement. The relative 766 delay in detected green-up date with respect to NASS reported emergence dates (Fig 13a and d) 767 is similar to that inferred at the field and district levels (Figs. 7 and 10). The median delay over 768 these counties was 17 days for corn and 9 days for soybean. Green-up was detected close to the 769 V3 physiological growth stage (approximately three leaves apparent), and occurred about 6-7 
770 days earlier for corn than for soybean for both years. The dormancy dates detected for corn were

771 between the reported maturation and harvest dates (Fig. 13b and 13e). The dormancy dates for

772 soybean were between the reported leaf-drop and harvest dates (Fig. 13c and 13f). Dormancy

773 dates of soybeans in some counties were very close to the leaf-drop stage, because the leaves at

774 the very top of the canopy may still be green at this stage (definition in section 2.3 ). The median

775 number of days between dormancy and harvest date for the 17 counties was 14-21 days and 6-8

776 days for corn and soybeans, respectively, which agrees with the statistics at the district level

777 from 2010 to 2014 (Sec. 4.3.2). The relative consistency between the remote sensing and

778 ground observer derived metrics demonstrated here suggest a reliable relationship between crop

779 growth stage and remote sensing phenology could be established for operational applications.
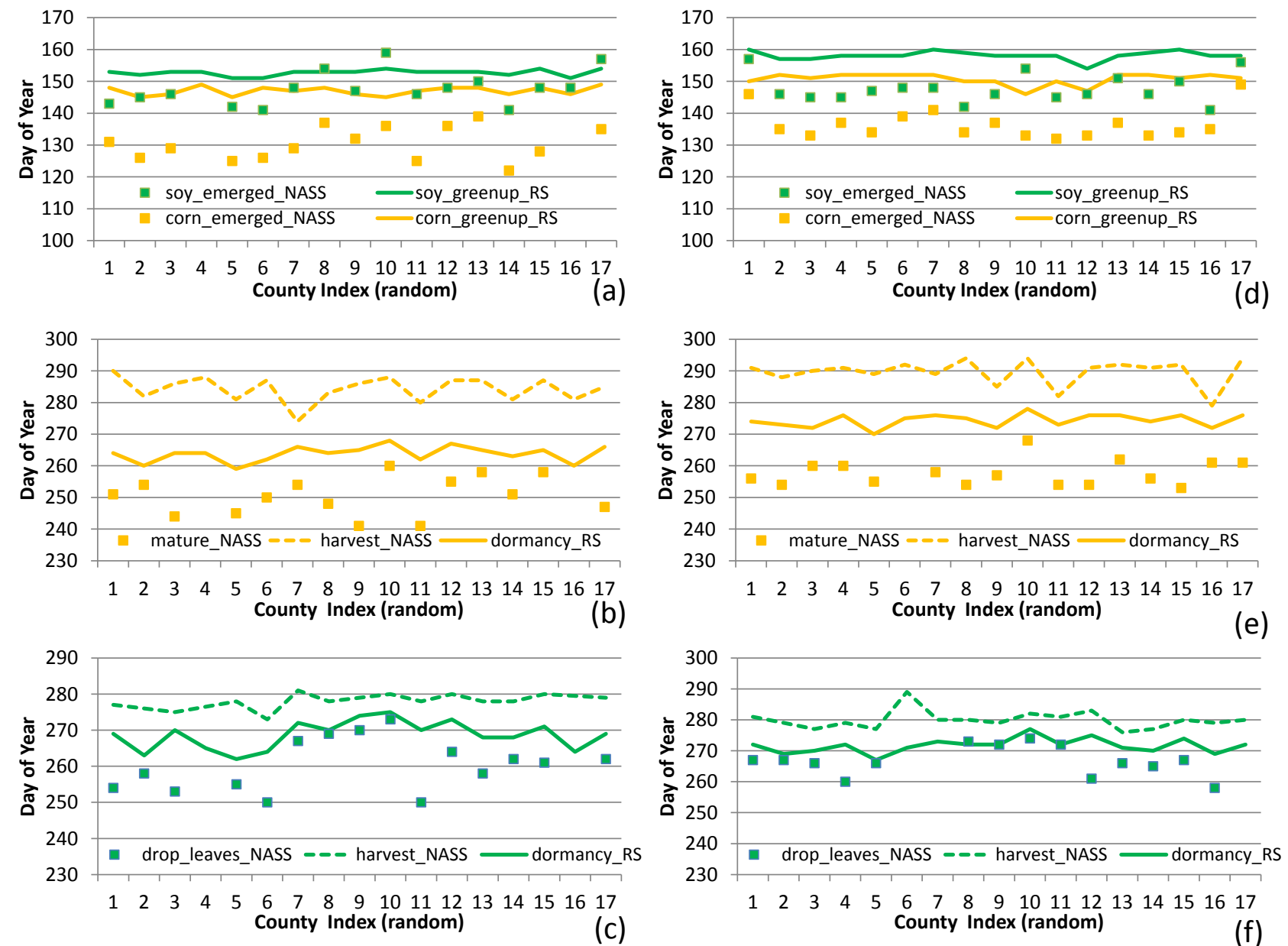

781 Fig. 13. Crop growth stages reported from 17 counties (county level, $x$-axis used random index) and

782 crop phenology extracted from remote sensing in 2010 (left) and 2011 (right). The emergence and 
green-up dates for corn and soybeans are compared in (a) and (d); the mature and harvest stages are compared to the dormancy date for corn in (b) and (e); the leaf-drop and harvest stages for soybeans are compared to the dormancy dates in (c) and (f).

\section{DISCUSSION}

787

788

789

790

791

792

793

794

795

796

797

798

799

800

801

802

803

804

805

806

807

808

809

810

The results presented in Sec. 4 show that crop phenology at field scales can be reasonably deduced by combining VI data from Landsat and MODIS. However, mapping of crop phenology at field scale is still challenging due primarily to the lack of clear observations available at the Landsat pixel resolution. Several limitations and opportunities for the proposed methodologies are discussed further below, associated with both the data fusion and the phenology extraction components of the integrated system.

\subsection{Data Fusion Limitations and Opportunities}

\subsubsection{Landsat Temporal Frequency}

A good seasonal distribution of clear Landsat-scale images is required for producing high quality data fusion results. In particular, Landsat imagery from the early growing season is critical since it provides remote sensing signals that can be used to separate different crop types. This is a typically rainy/cloudy period in the Corn Belt, and therefore in some years it is difficult to capture this early part of the season adequately with Landsat alone.

The recently launched Sentinel-2 satellite provides additional global Landsat-resolution imagery at no cost to users, which could be combined with Landsat data for mapping crop phenology. However, consistency of new data sources needs to be assessed. Differences in surface reflectance or NDVI may be caused by different sensor characteristics (e.g. spectral bandwidth) or data processing techniques (calibration and atmosphere correction). A normalization approach may be considered to convert surface reflectance from Landsat-resolution sensors to MODIS-like surface reflectance using MODIS NBAR data as a reference, as described in Gao et el. (2010). A relatively consistent timeseries data from different sensors could be more important than absolute inter-sensor calibration.

\subsubsection{Landsat-MODIS Mismatch}


811 Terra MODIS has a similar orbit to Landsat 7 ETM+ and thus MODIS and ETM+ images match

812 better than do other MODIS-Landsat combinations. However, ETM+ imagery after May 2003 is not

813 as useful for data fusion due to the SLC-off gaps. Landsat 8 OLI acquisition dates are 8 days apart

814 from Landsat 7, and Terra MODIS images are always acquired from off-nadir views at the Landsat 8

815 overpass time. In this study, we have corrected MODIS daily 250m directional surface reflectance to

816 daily NBAR (daily NBAR products at 500m resolution are now routinely available in the MODIS

817 Collection 6 reprocessing). However, off-nadir views also cause a reduction of spatial resolution in

818 the MODIS image and thus the MODIS data quality at off-nadir is lower when comparing to nadir

819 view (Tan et al., 2006). While we could exclude MODIS observations at large off-nadir views, this

820 would limit the temporal frequency of available MODIS imagery. A possible solution is to use Aqua

821 MODIS data to pair with Landsat 8 OLI imagery. The Aqua MODIS imagery is acquired at around

822 1:30 pm but has a smaller view zenith angle on Landsat 8 acquisition dates. The Aqua MODIS

823 imagery can be corrected to daily NBAR using the solar angles at the Landsat 8 overpass time. Since

824 Aqua MODIS and Landsat 8 OLI images are acquired at different times, cloud coverage could be

825 different in Landsat and MODIS images, which may limit their uses in the data fusion process.

826 Using a composite image generated from Aqua and Terra MODIS data may be another solution. As

827 MODIS sensors are aging, other coarse-resolution imagery such as the Visible Infrared Imaging

828 Radiometer Suite (VIIRS) may be used. The VIIRS sensor has a better spatial resolution at off-nadir

829 views, which could make it a good candidate for combination with (or replacement of) MODIS.

\section{$830 \quad 5.1 .3$ Computational Efficiency}

831 The STARFM program has recently been significantly improved in terms of computational 832 efficiency - this is of particular relevance to end-users using the original version of the system 833 (V1.1). In the original version, the entire STARFM algorithm had to be rerun for each prediction 834 date. In the current version, predictions for multiple MODIS dates that use the same Landsat835 MODIS input pair are combined into a single run (V1.2; Gao et al., 2015 - available freely online). 836 Therefore, the search time for spectrally similar pixels in the moving window (the most time837 consuming part) is greatly reduced. Testing demonstrated that the processing time for 30 predictions 838 using a single input pair reduced from 540 minutes to 78 minutes between V1.1 and 1.2, using a 839 single CPU (Intel Xeon 3.07GHz). In addition, parallel computing options implemented in this 840 version further reduced computing time to about 17 minutes for 30 predictions ( 31 times faster than 
841 V1.1). These improvements allow us to run the data fusion algorithm efficiently over an entire

842 Landsat scene on a personal Linux system. It took about a week on our computing system to

843 download and process Landsat and MODIS data for a single Landsat scene covering a whole year.

844 However, processing data over large areas (e.g. entire state or country) for multiple years is still a

845 challenge. High performance computing resources are needed for a large-area applications.

846

$847 \quad$ 5.2 Linking Remote Sensing with Physiological Growth Stages

848 This study explored and identified relationships that exist between phenological metrics that can

849 be derived from remote sensing and physiological stages of crop growth observed on the ground.

850 The latter information is directly usable in many applications, from yield prediction to farm

851 management. The next phase of this research will involve determining robust yet simple methods for

852 linking the remote sensing and physiological stages, to support crop progress monitoring over large

853 areas.

854 While a calendar date offset appeared to reasonably capture much of the variability between

855 remote sensing and physiological stages observed over central Iowa during the limited time period

856 studied here, a degree day model for connecting these stages may be more robust for large-area

857 monitoring. Particularly in the spring, the period between planting/emergence and the V3 stage

858 captured as "green-up" in the remote sensing data will largely be governed by degree day

859 accumulations within the Corn Belt.

$860 \quad$ Practically speaking, there is great potential utility for large area green-up maps, even though

861 the green-up signal lags actual planting and emergence dates. Planting/emergence could be

862 backcasted from green-up and used to check/adjust ground-based reports, which are typically based

863 on limited sparsely distributed samples. Planting/emergence is a critical variable in crop simulations,

864 used to forecast the impacts of weather, disease and pest on at-harvest yield, but it is very difficult to

865 obtain accurate planting and emergence dates from ground reports (Jones et al., 2003; Sacks et al.,

866 2010). Remote-sensing based backcasts may help to address these critical data issues in spatially

867 distributed crop modeling efforts.

868 Harvest typically occurs after the remotely sensed dormancy period, and therefore could be

869 forecasted. Remote sensing maps of dormancy, developed in real-time, could be used for harvest 
870 planning to reduce pre-harvest loss, especially for soybeans since they are fragile during harvest 871 time.

This study used NDVI time-series to detect green-up and senescent stages when NDVI has

873

874

875

876

877

878

879

880

881

882

883

884

885

886

887

888

889

890

891

892

893

894

895

896

897

898

899 not reached the saturation value. For crop stages during peak green season, other vegetation indices such as the Enhanced Vegetation Index (EVI) or two-band EVI (EVI2) may be more appropriate. Crop phenology detected using different vegetation indices may result in different phenological dates, and the relationships between phenology and crop growth stages may vary with index. These effects need to be further investigated.

Some crop growth stages may not be detectable from remote sensing signals directly. These stages may be determined using other ancillary information such as crop calendars and growing degree days. The two-step filtering approach of Sakamoto et al. $(2010,2011)$ uses a predefined shape model describing characteristic crop growth patterns as a priori information, fit to vegetation index time-series to capture dynamic conditions for a given growing season. The fitted shape model is then used to extract detailed phenological growth stages. Sakamoto et al. tested the approach using MODIS-derived vegetation index data at 250-m spatial resolution and daily timesteps. This approach could be extended to field scale using daily 30-m resolution fused Landsat-MODIS surface reflectance data to map growth stages at finer granularity than those investigated here.

Application of these methods in real-time is another area that requires additional research. Operationally, crop growth stages and conditions need to be reported weekly throughout the current growing season. The phenology programs used in this paper were not designed to map within-season crop phenology using partial years of data. However, the growth-shape model approach of Sakamoto et al. $(2010,2011)$ may be adaptable for real-time field-scale applications using fused LandsatMODIS timeseries.

\section{CONCLUSION}

The study presented here addressed three main objectives; the evaluation of fused LandsatMODIS reflectance and the derived vegetation index time-series, the use of these time-series to derive remote sensing metrics of crop phenology, and the investigation of connections between remote sensing metrics and physiological crop growth stages reported at field, county and district 
900 scales. The study combined the STARFM data fusion system with the MODIS time-series approach

901 for phenology extraction to produce maps of crop progress at 30-m resolution across an intensively

902 cropped area in central Iowa.

903 The STARFM approach was used to produce multi-year daily 30-m surface reflectance and

904 NDVI time-series which captured spatial and seasonal variability between the corn, soybean and

905 forested vegetation classes that characterize this region. Biases between fused and observed

906 Normalized Difference Vegetation Index (NDVI) were between -0.011 to 0.028 and mean absolute

907 differences were less than 0.083 for all years from 2001 to 2014 . These biases are due in part to

908 sensor, waveband, and view angle differences between Landsat and MODIS acquisitions, and it was

909 demonstrated that it is important to characterize these biases to fully understand performance of the

910 fusion output.

911 Using time-series of 30-m resolution NDVI maps derived from Landsat-MODIS data fusion,

912 crop phenological metrics were extracted using two established phenology programs (MODIS and

913 TIMESAT). While both approaches generated comparable metrics, the MODIS curvature approach

914 was deemed most practical for operational applications because it does not necessitate specification

915 of pre-defined thresholds, as required by the TIMESAT approach. Comparison with NASS crop

916 progress reports generated at the county and district levels shows that the remotely sensed crop

917 green-up dates were later than the reported emergence dates for all years, close to the V3 stage

918 where 2-4 leaves have developed. At this stage, rapid changes in satellite-derived NDVI signal were

919 most apparent. While this remotely sensible stage proceeds emergence, which is the date plants are

920 first visible from the ground, a high correlation between the two dates was found over the period

921 2010-2014, when the NASS crop progress reports at district level were available. This suggests

922 utility for robustly backcasting emergence from remote sensing, e.g. as input to crop simulation

923 models. The detected dormancy dates were 2-3 weeks ahead of harvest time for corn and about 1-2

924 weeks ahead for soybeans. The harvest times for individual fields may be predicted 1-3 weeks ahead

925 using remote sensing data, which could help to manage crop harvest at field level to reduce pre-

926 harvest loss.

927 This study demonstrated that time-series data from multiple remote sensing sources can be

928 effectively integrated and used to detect major crop physiological stages at the field scale. At 30-m

929 resolution, the phenology for corn and soybean crops can be clearly separated and quantified for 
930 field sizes typical in the United States. This capability has applications in farmland management and

931 yield prediction. However, routine mapping of crop growth stages within the season is still

932 challenging due to the fact that only a partial year of data is available for near real-time mapping.

933 Real-time applications will require an appropriate phenology approach and frequent clear-sky

934 remote sensing imagery. Satellite image data fusion can play a significant role in achieving this goal.

935

936

\section{ACKNOWLEDGEMENT}

937

This work was supported by the NASA Science of Terra and Aqua program

938 (NNH13ZDA001N-TERAQ) and the US Geological Survey (USGS) Landsat Science Team

939 program. The collection of field biophysical data was funded by NASA grant NNX09AO14G.

940 USDA is an equal opportunity provider and employer. 


\section{REFERENCES}

Boryan, C., Yang, Z., Mueller, R., \& Craig, M. (2011). Monitoring US agriculture: the US Department of Agriculture, National Agricultural Statistics Service, Cropland Data Layer Program. Geocarto International, 26(5), 341-358.

Feng, M., Sexton, J., Huang, C., Masek, J., Vermote, E., Gao, F., Narasimhan, R., Channan, S., Wolfe, R., \& Townshend, J. (2013). Global surface reflectance products from Landsat: Assessment using coincident MODIS observations. Remote Sensing of Environment, 134, 276-293.

Friedl, M. A., McIver, D. K., \& Hodges, J. C. F. etc. (2002). Global land cover from MODIS: Algorithms and early results. Remote Sensing of Environment, 83, 287-302.

Gao, F., Masek, J., Schwaller, M., \& Hall, F. (2006). On the Blending of the Landsat and MODIS Surface Reflectance: Predict Daily Landsat Surface Reflectance. IEEE Transactions on Geoscience and Remote Sensing, 44(8), 2207-2218.

Gao, F., Morisette, J. T., Wolfe, R. E., Ederer, G., Pedelty, J., Masuoka, Ed., Myneni, R., Tan, B., \& Nightingale, J. (2008). An Algorithm to Produce Temporally and Spatially Continuous MODIS LAI Time Series. IEEE Geoscience and Remote Sensing Letters, 5(1), 60-64.

Gao, F., Masek, J., Wolfe, R., \& Huang, C. (2010). Building consistent medium resolution satellite data set using moderate resolution imaging spectroradiometer products as reference. Journal of Applied Remote Sensing, 4, 043526, doi: 10.1117/1.3430002.

Gao, F., Hilker, T., Zhu, X., Anderson, M., Masek, J., Wang, P., \& Yang, Y. (2015). Fusing Landsat and MODIS Data for Vegetation Monitoring. IEEE Geoscience and Remote Sensing Magazine, 3(3), 47-60.

Goring, D. G. \& Nikora, V. I. (2002). Despiking acoustic doppler velocimeter data. Journal of Hydrologic Engineering, 128, 117-26.

Hilker, T., Wulder, M. A., Coops, N. C., Linke, J., McDermid, G., Masek, J. G., Gao, F. \& White, J. C. (2009). A new data fusion model for high spatial- and temporal- resolution mapping of forest disturbance based on Landsat and MODIS. Remote Sensing of Environment, 113(8), 1613-1627. 
Jones, J.W., Hoogenboom, G., Porter, C.H., Boote, K.J., Batchelor, W.D., Hunt, L.A., Wilkens, P.W., Singh, U., Gijsman, A.J., \& Ritchie, J.T. (2003). DSSAT cropping system model. European Journal of Agronomy, 18, 235-265.

Jonsson, P. \& Eklundh, L. (2004). TIMESAT - a program for analysing time-series of satellite sensor data. Computers and Geosciences, 30, 833-845.

Kucharik, C.J. (2006). A multidecadal trend of earlier corn planting in the central USA. Agronomy Journal, 98(6), 1544-1550.

Liang, L., Schwartz, M., Wang, Z., Gao, F., Schaaf, C., Tan, B., Morisette, J., \& Zhang, X. (2014). A cross comparison of spatiotemporally enhanced springtime phenological measurements from satellites and ground in a northern U.S. mixed forest. IEEE Transactions on Geoscience and Remote Sensing, 52(12), 7513-7526. doi: 10.1109/TGRS.2014.2313558.

Lehecka, G. V. (2014). The value of USDA crop progress and condition information: reactions of corn and soybeans futures markets. Journal of Agricultural and Resource Economics, 39(1), 88-105.

Loveland, T.R. \& Dwyer, J.L. (2012). Landsat-building a strong future. Remote Sensing of Environment, 122, 22-29.

Masek, J. G., Vermote, E. F., \& Saleous, N. E. etc. (2006). A Landsat surface reflectance data set for North America, 1990-2000. IEEE Geoscience and Remote Sensing Letters, 3(1), 69-72.

NASS CPR (2015). http://www.nass.usda.gov/Publications/National_Crop_Progress/ (last accessed November 30, 2015)

NASS

Bulletin (2007). http://www.nass.usda.gov/Statistics_by_State/Iowa/Publications/Annual_Statistical_Bulletin/2008/4 5_08.pdf (last accessed November 30, 2015)

NASS CDL (2015). http://www.nass.usda.gov/Research_and_Science/Cropland/SARS1a.php (last accessed November 30, 2015) 
NASS Field Crops Usual Planting and Harvesting Dates (1997) http://usda.mannlib.cornell.edu/usda/current/planting/planting-10-29-2010.pdf (last accessed November 30, 2015)

NASS Field Crops Usual Planting and Harvesting Dates (2010) http://usda.mannlib.cornell.edu/usda/nass/planting//1990s/1997/planting-12-05-1997.pdf (last accessed November 30, 2015)

NASS

Terms

http://www.nass.usda.gov/Publications/National_Crop_Progress/Terms_and_Definitions/

(last accessed November 30, 2015)

Reed, B.C., Brown, J.F., Vander Zee, D., Loveland, T.R., Merchant, J.W., \& Ohlen D.O. (1994). Measuring phenological variability from satellite imagery. Journal of Vegetation Science, 5, 703714.

Ren, J., Campbell, J. B., \& Shao, Y. (2014). Agricultural land use changes, 2001-2012, southeastern Iowa, using Landsat 4 \&5 TM imagery. ASPRS 2014 Annual Conference Proceedings, Louisville, Kentucky, USA, March 2014 (http://www.asprs.org/a/publications/proceedings/Louisville2014/Ren.pdf , last accessed November $30,2015)$

Richardson, A. D., Braswell, B. H. Hollinger, D. Y. Jenkins J. P., \& Ollinger, S. V. (2009). Nearsurface remote sensing of spatial and temporal variation in canopy phenology. Ecological Applictions, 19(6), 1417-1428.

Roy, D.P., Wulder, M.A., \& Loveland, T.R. etc. (2014). Landsat-8: Science and product vision for terrestrial global change research. Remote Sensing of Environment, 145, 154-172.

Sacks, W.J., Deryng, D., Foley, J.A., \& Ramankutty, N. (2010). Crop planting dates: an analysis of global patterns. Global Ecology and Biogeography, 9, 607-620.

Sakamoto, T., Wardlow, B. D., Gitelson, A. A., Verma, S. B., Suyker, A. E., \& Arkebauer, T. J. (2010). A Two-Step Filtering approach for detecting maize and soybean phenology with time-series MODIS data. Remote Sensing of Environment, 114, 2146-2159. 
Sakamoto, T., Wardlow, B. D., \& Gitelson, A. A. (2011). Detecting spatiotemporal changes of corn developmental stages in the US Corn Belt using MODIS WDRVI data. IEEE Transactions on Geoscience and Remote Sensing, 49, 1926-1936.

Sakamoto, T., Gitelson, A. A., Arkebauer, T. J. (2013). MODIS-based corn grain yield estimation model incorporating crop phenology information. Remote Sensing of Environment, 131, 215-231.

Schaaf, C. L. B., Gao, F. \& Strahler, A. H. etc. (2002). First operational BRDF, albedo and nadir reflectance products from MODIS. Remote Sensing of Environment, 83, 135-148.

Schaaf, C. L. B., Liu, J., Gao F., \& Strahler, A. H. (2011). MODIS Albedo and Reflectance Anisotropy Products from Aqua and Terra, In Land Remote Sensing and Global Environmental Change: NASA's Earth Observing System and the Science of ASTER and MODIS, Remote Sensing and Digital Image Processing Series, Vol.11, B. Ramachandran, C. Justice, M. Abrams, Eds, Springer-Cerlag, 873 pp.

Tan, B., Woodcock, C. E., \& Hu, J. etc. (2006). The impact of gridding artifacts on the local spatial properties of MODIS data: Implications for validation, compositing, and band-to-band registration across resolutions. Remote Sensing of Environment, 105, 98-114.

Toomey, M., Friedl, M. A., \& Frolking, S. etc. (2015). Greenness indices from digital cameras predict the timing and seasonal dynamics of canopy-scale photosynthesis. Ecological Applications, 25:99-115.

Vermote, E. F., El Saleous, N. Z., \& Justice, C. O. (2002). Atmospheric correction of MODIS data in the visible to middle infrared: first results. Remote Sensing of Environment, 83, 97-111.

Walker, J., Beurs, K. M., Wynne, R. H., \& Gao, F. (2012). Evaluation of Landsat and MODIS data fusion products for analysis of dryland forest phenology. Remote Sensing of Environment, 117, 381393. doi:10.1016/j.rse.2011.10.014.

Walthall, C.L., Hatfield, J., \& Backlund, P. etc. (2012). Climate change and agriculture in the United States: Effects and adaptation. USDA Technical Bulletin 1935. Washington, DC. 186 pages.

Wang, P., Gao, F. \& Masek, J. (2014) Operational data fusion framework for building frequent Landsat-like images. IEEE Transactions on Geoscience and Remote Sensing, 52(1), 7353-7365. 
Woodcock, C. E., Allen, R., Anderson, M., Belward, A., Bindschadler, R., Cohen, W. B., Gao, F., Goward, S. N., Helder, D., Helmer, E., Nemani, R., Oreopoulos, L., Schott, J., Thenkabail, P. S., Vermote, E. F., Vogelmann, J., Wulder, M. A., \& Wynne, R. (2008). Free access to Landsat imagery. Science, 320, 1011.

Xiao, X., Hollinger, D., Aber, J., Goltz, M., Davidson, E. A., Zhang, Q., \& Moore, B. (2004). Satellite-based modeling of gross primary production in an evergreen needleleaf forest. Remote Sensing of Environment, 89, 519-534.

Zhang, X., Friedl, M.A., Schaaf, C.B., Strahler, A.H., Hodges, J.C.F., Gao, F., \& Reed, B.C (2003). Monitoring vegetation phenology using MODIS. Remote Sensing of Environment, 84(3), 471-475.

Zhang, X. (2015). Reconstruction of a complete global time series of daily vegetation index trajectory from long-term AVHRR data. Remote Sensing of Environment, 156, 457-472.

Zhao, H., Yang, Z., Di, L., Li, L., \& Zhu, H. (2009). Crop phenology date estimation based on NDVI derived from the reconstructed MODIS daily surface reflectance data. Geoinformatics, 2009 17th International Conference on, doi: 10.1109/GEOINFORMATICS.2009.5293522.

Zhao, H., Yang, Z., Di, L., \& Pei, Z. (2012). Evaluation of temporal resolution effect in remote sensing based crop phenology detection studies. Computer and Computing Technologies in Agriculture V the series IFIP Advances in Information and Communication Technology, 369, 135150.

Zhu, X., Chen, J., Gao, F. \& Masek, J. (2010). An enhanced spatial and temporal adaptive reflectance fusion model for complex heterogeneous regions. Remote Sensing of Environment, 114, 2610-2623.

Zhu, Z. \& Woodcock, C. E. (2012). Object-based cloud and cloud shadow detection in Landsat imagery. Remote Sensing of Environment, 118, 83-94.

Zhu, Z. \& Woodcock, C. E. (2015). Improvement and expansion of the Fmask algorithm: cloud, cloud shadow, and snow detection for Landsats 4-7, 8, and Sentinel 2 images. Remote Sensing of Environment, 159, 269-277. 